\title{
One-way and quasi-periodic climate changes: Geologic evidence
}

\author{
N. M. Chumakov \\ Geological Institute, Russian Academy of Sciences
}

\begin{abstract}
During the last three billion years, the Earth has been experiencing a slow global cooling, expressed in the progressively increasing frequency and scale of glacial events. Based on these indications, geologic history can be divided into three climatic stages: (a) nonglacial (Early and Middle Archean), (b) with episodic glaciations (Late Archean to Middle Riphean), and (c) with frequent periodic glaciations (Late Riphean-present). The cooling has apparently been caused by changes in the density and composition of the atmosphere, by the waning of heat flow from the Earth's interior, and by an increase in the planet's albedo in response to continental growth. The irreversible climate trend was modulated and obscured by numerous superposed temperature oscillations of varying periodicity and amplitude. A broad spectrum of such oscillations, from ultralong-term (a few hundreds of million years) to decadal-scale, have been established. The Phanerozoic exhibits a hierarchy of coordinated periods of climatic oscillations of 10-12 ranks. Climatic oscillations of the first two or three ranks are to be detected in Proterozoic glacial sequences. In light of the above, the Earth's climate history appears to be naturally determined, the slow irreversible cooling of the Earth's surface being superposed by a rather regular pattern of periodic oscillations. The inference suggests itself that the Earth's highly complex and open climate system has been rather close to a stationary state, and that among the multitude of nonlinear processes bearing on climate there were a small number of those most influential, "governing" processes with periodic attractors. Glaciation maxima preceded principal tectonic phases, and they are clearly correlative to suprasubduction volcanic maxima, whereas the periods of degradation or cessation of glaciation coincide with tectonic, granitization, metamorphic, and, occasionally, mantle-plume volcanic maxima. This suggests that onsets of glaciation were triggered by explosive volcanism and by the ensuing volcanic winters. Deglaciations must have been due to increases in atmospheric transparency, to carbon oxidation and partial decarbonatization in sedimentary sequences of orogens, and to pulses of mantle plume volcanism. A similar explanation applies to long-term climatic oscillations that lasted 30 m.y. on average. Short-term climatic oscillations are explicable by variations in the astronomical parameters of our planet, and ultrashort-term ones, apparently, by solar activity variations.
\end{abstract}

\section{Introduction}

Copyright 2002 by the Russian Journal of Earth Sciences.

Paper number TJE02088.

ISSN: $1681-1208$ (online)

The online version of this paper was published 23 July 2002. URL: http://rjes.wdcb.ru/v04/tje02088/tje02088.htm
The Earth's climate system is a very complex open system influenced by numerous external and internal factors. This is the reason why our planet's climate history is not infrequently seen apriori as resulting from a multitude of processes and as being a succession of nearly random events. Such notions are amply supported by numerous hypothe- 
ses in circulation that offer a range of explanations for the causes of climate changes and that are sometimes at variance with each other and with geologic record. This record itself shows, however, that the Earth's climate history is not as chaotic as might seem, and that certain regularities are discernible in it. These regularities have become more evident now that paleoclimatology has strongly expanded its factographic and methodological base and has undergone qualitative changes. Abundant paleoclimatic evidence has been acquired in recent decades through the study of circumpolar and other hard-access areas and by ocean drilling. Among new approaches and methods, of the paramount importance are mobilist paleoclimate reconstructions, stable isotope geochemistry, computer climate modeling, very detailed quantitative studies of sedimentary sequences using various methods, the multivariate mathematical analysis of the conditions of formation of indicator rocks, and the morphology of fossil plant leafs.

The new facts and ideas afford a more detailed consideration of Phanerozoic climates, a general review of the Earth's climate history over the last three billion years, and an attempt to find out how systematic climate changes have been and how consistent they are with the notions of a complex and open structure for the Earth's climate system.

\section{The General Trend of Climate Changes}

1.1. Glaciations through geologic history. The trend of climate changes on Earth can be unraveled using the most striking climatic events-glaciations. Their frequency and scale have been growing strongly over time (Figure 1). Such a nonuniform distribution of glaciations cannot be a mere artifact of insufficient knowledge of the older strata. The chase after strategic minerals in the Cold War years boosted detailed geologic mapping and exploration on nearly all the terranes composed of ancient rocks worldwide, including poorly developed countries. A variety of economic mineral deposits were then discovered. Exploration as detailed as that would hardly have failed to spot glacial deposits, especially tillites, which commonly make large bodies, are of regional extent, and which catch geologists' attention by their extraordinary aspect and origin. Besides, in the Precambrian, tillites often serve as important stratigraphic markers. For these reasons, the finds of ancient glacial deposits or resembling rocks are invariably documented in the course of mapping projects. The suggestion that glaciation frequency has really been increasing through time is further supported by two additional considerations: (1) the scale of glaciations has been increasing as well, and their history has been growing ever more complex through time, and (2) although over the past 30-40 years, the age and areal distribution of glacial deposits have been constrained essentially, virtually no single new glacial level has been discovered. The inference that Precambrian glaciations started in the Early Archean $^{1}$ (3460 Ma BP) and then recurred every 400-370

\footnotetext{
${ }^{1}$ This work makes use of the Russian stratigraphic terminology and a Russian geochronologic scale for the Precambrian [Reshe-
}

m.y. [Steiner, 1978] has not been validated ${ }^{2}$. It thus would be reasonable to assume that the available data on glacial periods (Table 1) portray well enough the actual distribution of glaciations through geologic history.

No convincing indications for Early Archean glaciations are known yet. The earliest glaciation traces, still very sparse and spatially limited, have been reported from the Late Archean Witwatersrand Supergroup [Hambrey et al., 1981] and from the Mozaan Group [Young et al., 1998] within the rather small Kaapvaal craton, South Africa. These glaciations are dated at ca. 2.9 Ga [Nelson et al., 1999]. The Witwatersrand glaciation, in all likelihood, was of a mountain or piedmont nature, whereas the Mozaan glaciation was of the sheet type, judging by the appreciable amount of dropstones (evidence of iceberg rafting) encountered in this Group.

Subsequent glaciations did not occur until the Early Proterozoic, i.e., 600-700 m.y. after the Late Archean ones. Early Proterozoic glaciations were much larger in scale and were dominantly sheet glaciations. Their deposits have been detected on as many as four continents far off each other - on the Canadian shield [Young, 1970], in South Africa [Visser, 1981], on the Baltic shield [Marmo and Ojakangas, 1984], and in Western Australia [Eriksson et al., 1999; Martin, 1999]. The totality of abundant radiometric data constrain the age of these glacial deposits to a rather narrow interval of 2.3-2.2 Ga [Crowell, 1999]. Uniform carbon isotope anomalies associated with carbonate rocks upsection from the glacial deposits corroborate the overall synchroneity of the latter [Bekker et al., 2001; Semikhatov et al., 1999]. In North America, Early Proterozoic glacial deposits have been reported from several regions far away from each other. In the vicinity of the Great Lakes, the Huronian Supergroup contains deposits of three major glacial epochs with interglacial beds in-between. The upper glacial epoch, that of the Gowganda Formation, in turn consisted of two glacial events [Young, 1970].

In the higher horizons of the Lower Proterozoic, in the Lower and most of the Middle Riphean, no trustworthy traces of glaciations have been spotted. This stratigraphic interval, which spanned ca. 1 to 1.2 billion years and which is at times referred to as a "glacial pause," is also devoid of major carbon isotope anomalies [Bekker et al., 2001], which is indirect evidence for the lack of glaciations. Sporadic reference to the presence of dispersed boulders in the upperLower Proterozoic, judging from the concise published descriptions [Akhmedov, 2001; Salop, 1973; etc.], most likely suggests volcanic slump-related phenomena or seasonal ice rafting, i.e., at most, a moderately cool climate, and not glaciation ${ }^{3}$.

nie..., 2001; Semikhatov, 2000; Semikhatov et al., 1991]. For the Phanerozoic, adopted is the geologic time scale of Harland et al. [1990], refined for the Cambrian [Semikhatov, 2000].

${ }^{2}$ Especially considering the lack of geologic evidence for a longterm global glaciation of the early Earth, proposed in connection with the "weak" early Sun.

${ }^{3}$ Should it be proved that some of the boulder-bearing shales in the upper-Lower Proterozoic are of glacial origin, this would not affect the fundamental corollary that the frequency and scale of glaciations in the post-Archean geologic history have been increasing. 


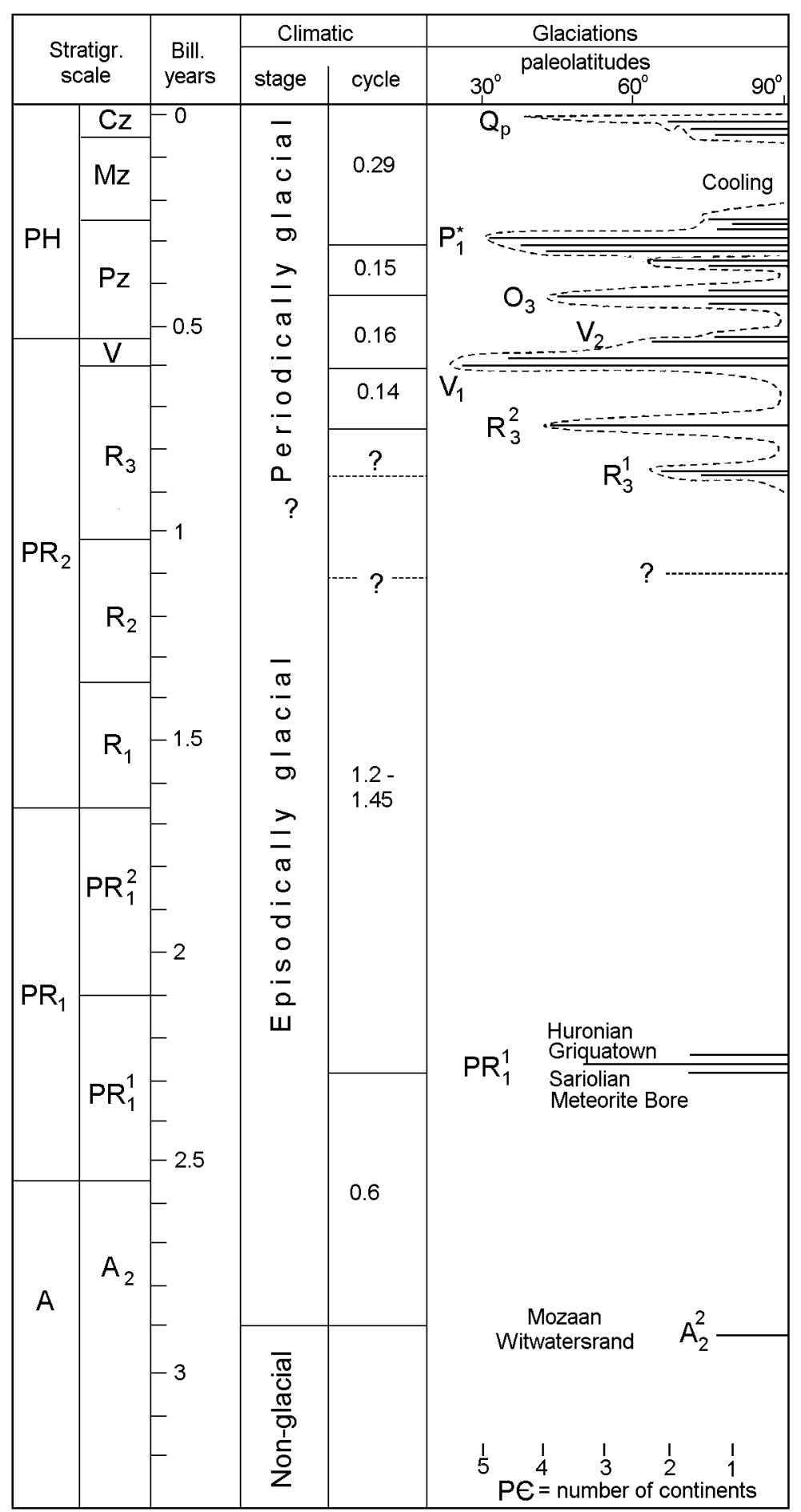

Figure 1. Distribution of glaciations through geologic history. Solid horizontal lines, glacial epochs (glacioepochs); their length is proportionate to the maximum spread of glaciation in a given epoch (in the Phanerozoic, to paleolatitudes, and in the Precambrian, to the number of continents). Dashed line outlining glacioepochs shows glacial periods (glacioperiods). Dotted lines, inferred glaciations and ages. $\mathrm{A}=$ Archean, $\mathrm{PR}=$ Proterozoic, $\mathrm{R}=$ Riphean, $\mathrm{V}=$ Vendian, $\mathrm{PH}=$ Phanerozoic. $\mathrm{MC}=\mathrm{Mesozoic}$ cooling (modified after [Chumakov, 2001a]). 
Table 1. Glacial and non-glacial climate periods and concomitant events

\begin{tabular}{|c|c|c|c|c|c|c|c|c|}
\hline $\begin{array}{l}\text { Age } \\
(\mathrm{Ma})\end{array}$ & $\begin{array}{c}\text { Glacial }=\mathrm{g} ; \\
\text { non-glacial }=\mathrm{t}\end{array}$ & $\begin{array}{l}\text { Duration } \\
\text { (m.y.) }\end{array}$ & $\begin{array}{c}\text { Polar } \\
\text { continents }^{2}\end{array}$ & Supercontinents ${ }^{1}$ & $\begin{array}{c}\mathrm{CO}_{2} \text { content } \\
\mathrm{n}^{3}\end{array}$ & tectonic $^{4}$ & $\begin{array}{c}\text { Maxima } \\
\text { volcanic } \\
\text { suprasubduction }\end{array}$ & $\begin{array}{c}\text { mantle } \\
\text { plume }\end{array}$ \\
\hline 0 & & & & & & & & \\
\hline $\begin{array}{c}\mathrm{Cz}_{2} \\
40\end{array}$ & ggggg & 40 & $\begin{array}{c}++ \\
+\end{array}$ & + & 1 & + & + & \\
\hline $\mathrm{Cz}_{1}-\mathrm{Mz}$ & $\mathrm{t}$ & 205 & ++ & ++ & $5-7$ & & & ++ \\
\hline $\begin{array}{l}245 \\
\mathrm{P}^{2}\end{array}$ & & & & & & ++ & & \\
\hline $\begin{array}{l}\mathrm{Pz}_{3}^{2} \\
323\end{array}$ & ggggg & 78 & ++ & ++ & 1 & + & & \\
\hline $\begin{array}{c}\mathrm{C}_{1} \\
353\end{array}$ & $\mathrm{t}$ & 30 & ++ & + & $2-4$ & & & \\
\hline $\begin{array}{c}\mathrm{C}_{1}-\mathrm{D}_{3} \\
367\end{array}$ & ggggg & 14 & ++ & + & $4-7$ & & + & \\
\hline $\begin{array}{c}\mathrm{D}_{3}-\mathrm{S}_{3} \\
426\end{array}$ & $\mathrm{t}$ & 59 & + & + & $7-12$ & ++ & & + \\
\hline $\begin{array}{c}\mathrm{S}_{2}-\mathrm{O}_{3} \\
444\end{array}$ & ggggg & 18 & + & + & $12-17$ & + & + & \\
\hline $\begin{array}{c}\mathrm{O}_{3}-\mathrm{Cm}_{1} \\
530\end{array}$ & $\mathrm{t}$ & 86 & + & + & & & & \\
\hline $\begin{array}{c}\mathrm{Cm}_{1}^{1}-\mathrm{V}_{2}^{2} \\
540\end{array}$ & $\mathrm{gg}$ & $10 ?$ & + & + & & & & \\
\hline $\begin{array}{c}\mathrm{V}_{2} \\
585\end{array}$ & $\mathrm{t}$ & 45 & + & & & & & + \\
\hline $\begin{array}{c}\mathrm{V}_{1}^{1} \\
600\end{array}$ & ggggg & $15 ?$ & + & + & & & & \\
\hline $\begin{array}{c}\mathrm{R}_{3}^{2-3} \\
740\end{array}$ & $\mathrm{t}$ & 140 & & & & & & + \\
\hline $\begin{array}{c}\mathrm{R}_{3}^{2} \\
760\end{array}$ & ggggg & $20 ?$ & & + & & & & \\
\hline $\begin{array}{c}\mathrm{R}_{3}^{1-2} \\
890\end{array}$ & $\mathrm{t}$ & 130 & & ++ & & & & + \\
\hline $\begin{array}{c}\mathrm{R}_{3}^{1} \\
910\end{array}$ & ggg & $20 ?$ & & & & & & + \\
\hline $\begin{array}{c}\mathrm{R}_{3 /-2}^{1}-\mathrm{PR}_{1}^{2} \\
2200\end{array}$ & $\mathrm{t}$ & 1290 & & & & & & + \\
\hline $\begin{array}{l}\mathrm{PR}_{1}^{2} \\
2300\end{array}$ & gggg & 100 & & & & & & \\
\hline $\begin{array}{c}\mathrm{PR}_{1}^{1}-\mathrm{Ar}_{3} \\
2900\end{array}$ & $\mathrm{t}$ & 600 & & & & & & + \\
\hline $\begin{array}{c}\mathrm{Ar}_{3}^{2} \\
2950\end{array}$ & ggg & $50 ?$ & & & & & & \\
\hline
\end{tabular}

${ }^{1}$ Single symbol, supercontinent of the Gondwana type, and twin symbols, of the Pangea type. ${ }^{2}$ Single symbol, at one pole; twin symbols, at both poles. ${ }^{3} \mathrm{n}$ - modern atmospheric $\mathrm{CO}_{2}$ content. ${ }^{4}$ Single symbol, considerable; twin symbols, maximal final. ${ }^{5}$ The number of characters is roughly proportionate to glaciation scale.

It is not clear enough whether or not any glaciations took place in the Middle Riphean. On the Baikal-Patom Highland and in Brazil, glacial deposits occur that may be dated to the Middle or Late Riphean [Chumakov, 1993a; D'Agrella-Filho et al., 1990; Khomentovsky and Postnikov, 2001]. Starting in the Late Riphean on to the present, glaciations have occurred on the Earth regularly and on an increasing scale. At their maxima, glaciations covered vast areas on as many as four or five of the present-day continents at once, occasionally reaching as low as lat. $40^{\circ}-30^{\circ}$ or even somewhat closer to the equator ${ }^{4}$. With time, the structure of glacial periods grew in complexity as well, which was ex-

${ }^{4}$ Note however that the hypothesis of global glaciations in the Vendian and Late Riphean [Harland, 1964; Hoffman et al., 1998; etc.] cannot be deemed proven yet [Chumakov, 1992; Crowell, 1999; Smith, 2001; etc.], because it is still based on sporadic [Evans, 2000) and questionable [Meert and van der Voo, 1995] paleomagnetic measurements. 


\section{GEODYNAMIC SETUP}

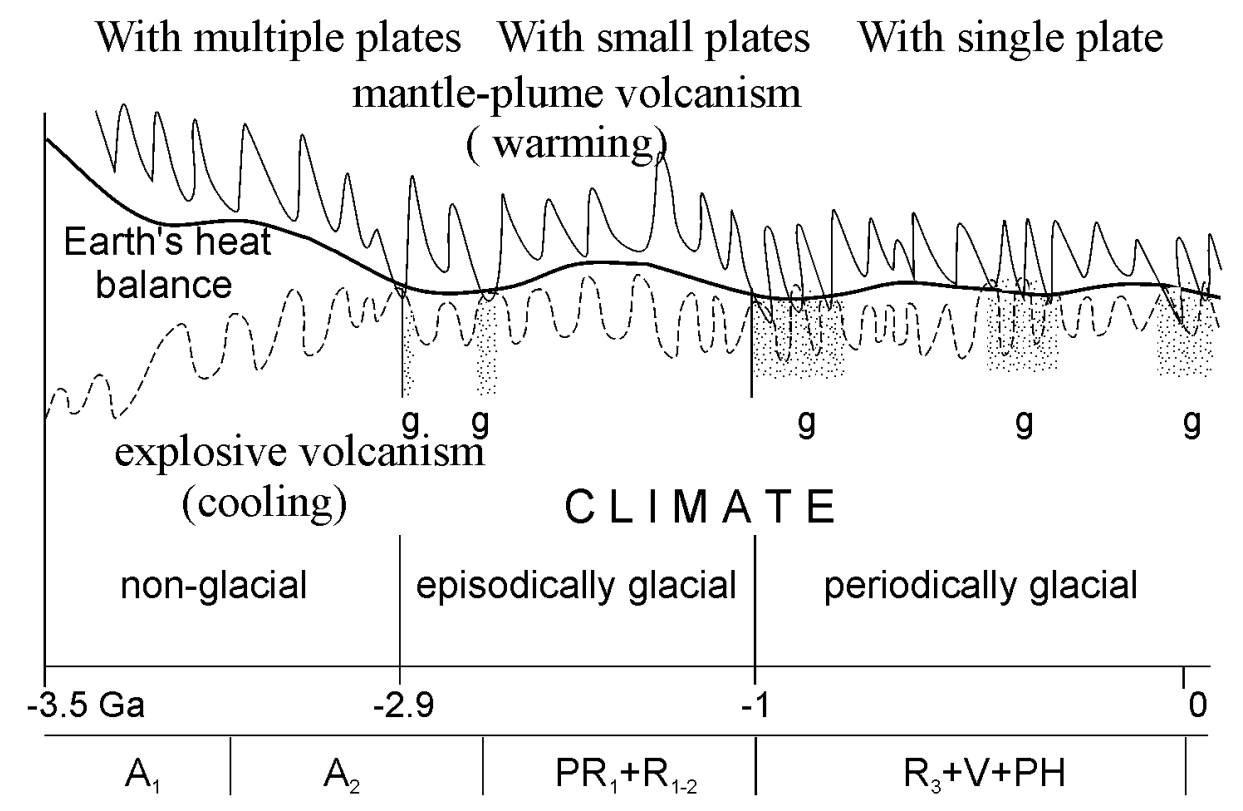

Figure 2. Hypothetical relationships among the irreversible cooling of the Earth's surface, character of volcanism, explosive volcanic maxima, major periodic coolings and mantle- plume volcanic maxima, warming, and geodynamic stages [Chumakov, 2001b]. $\mathrm{g}=$ glaciations, $\mathrm{A}=$ Archean, $\mathrm{PR}=$ Proterozoic, $\mathrm{R}=$ Riphean, $\mathrm{V}=$ Vendian, $\mathrm{PH}=$ Phanerozoic.

pressed in the multiplicity of glacial epochs and their subordinate smaller glacial events.

Therefore, over the last three billion years, the trend of climate changes on Earth has been toward a progressively greater role for glacial climate. This testifies to slow cooling of our planet's surface. Over the first two billion years, glaciations occurred rarely. The total duration of ice ages constituted no more than $7 \%$ of this timespan. At ca. $1 \mathrm{Ga}$ $\mathrm{BP}$, the cooling became appreciably stronger, with ice ages accounting for ca. $25 \%$ of this time interval, and in the Phanerozoic (i.e., over the last 535 m.y.), for as much as $30 \%$ (see Table 1).

Based on the above facts and considerations, the Earth's climate history can be divided into three qualitatively distinct stages [Chumakov, 2001b]: (1) non-glacial, Early Archean; (2) with sporadic episodic glaciations, Late Archean to Middle Riphean; (3) with frequent periodic glaciations, Late (or Middle) Riphean to the present.

1.2. Causes of the Earth's cooling. The following causes are likely to be responsible for the cooling of the Earth's surface and for the existence of the three climate stages just proposed. The chief cause of the cooling was apparently slow lowering of the Earth's heat balance (Figure 2). Partially, this may have been due to waning heat flow from the Earth's interior as a result of mantle cooling [Dobretsov and Kovalenko, 1995] owing to a decline in radiogenic heat generation, to deceleration of gravitational differentiation processes, and to a decrease in the tidal deformations in subcrustal shells of the Earth. Another cause of cooling may have been a density reduction of and compositional changes in the atmosphere, especially, a drop in the greenhouse gases content. Lastly, a certain role may have been played by increase of the planet's albedo with progressive continental growth. The postulated slow increase in solar luminosity, apparently, made up only partially for the listed processes of reduction of the heat balance of the Earth's surface.

1.3. Nature of the climatic stages. The rather slow process of cooling of the Earth's surface was modulated by a complex system of periodic climatic oscillations, whose structure and nature are addressed in the following section. At this point, it should be noted that during the first, non-glacial climate stage the Earth's surface evidently had a large positive heat balance that ensured a warm climate at any periodic cooling events. During the second stage, the heat balance of the Earth's surface was reduced, and individual major cooling events overpowered it, with resultant episodic glaciations. By the onset of the third stage, the Earth's climate system had approached equilibrium between its non-glacial and glacial states (Figure 2), such that in post-Middle Riphean geologic history the periodic cooling events caused frequent and systematic alternations of glacial and non-glacial periods and epochs. Therefore, the slow, in fact evolutionary, process of cooling of the Earth's surface led to qualitative changes as regards the types of climate.

Interestingly, the three climate stages here proposed coincide approximately with the three stages of the onset of plate tectonics on Earth [Khain, 1995, 2001]. This implies a certain parallelism between the geotectonic and climatic evolutions of Earth and a dependency of these two on the intensity of tectonic, magmatic, and metamorphic processes. 

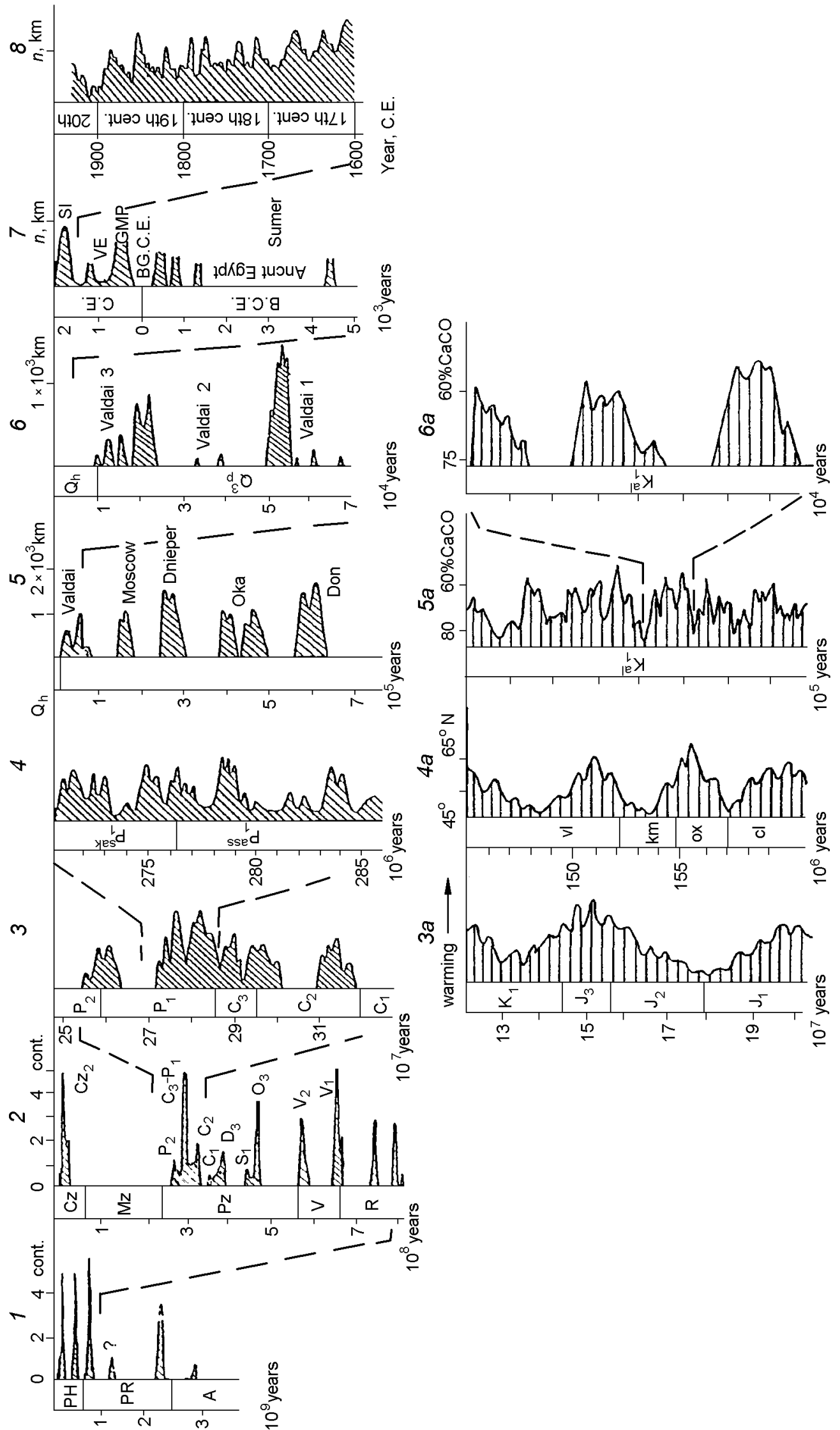


\section{Periodic Climate Changes}

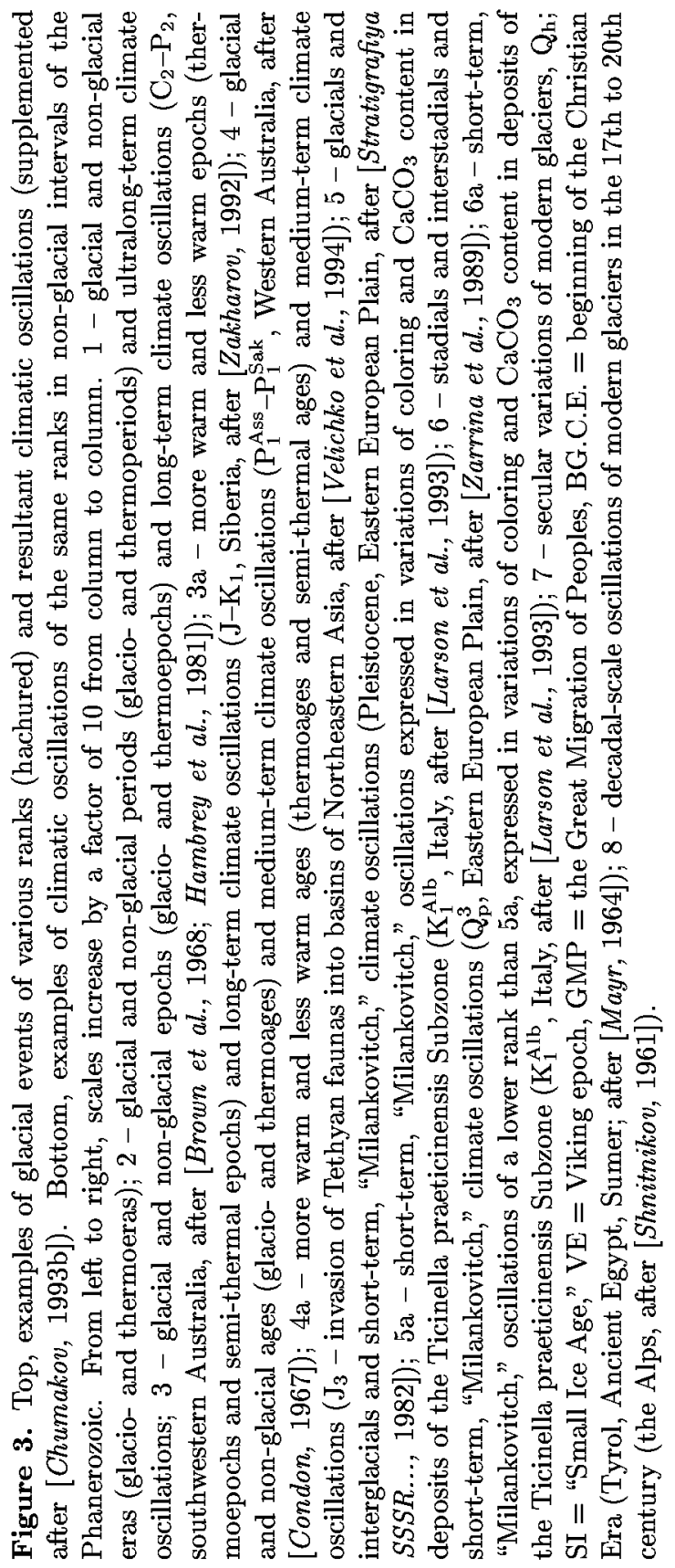

As mentioned above, the general trend of the Earth's surface cooling has not been unidirectional. It has been complicated and obscured by numerous positive/negative and scale-variable climate changes. The overwhelming majority of these changes occurred within certain bounds and, after a time, ended coming back close to the initial state. For this reason, all or nearly all the climate changes can be viewed as periodic oscillations, to a first approximation. The reservation should be made that the periodicity concept is here used in its very broad sense, as it is commonly applied in geoscience. In reality, these oscillations were not strictly periodic or harmonic, and, consequently, they were not linear. This is evidenced by the character of the detailed climate time series and by occasional bifurcations in oscillation periods, as detected through their spectral-temporal analysis [Chumakov and Oleinik, 2001]. Strictly speaking, such oscillations should be termed quasi-periodic, self-similar, or similar. With this well in mind, following the long-standing custom among geologists, we will call them periodic just the same, for the reader's convenience and to avoid confusion.

Periodic oscillations of climate, especially of its temperature characteristics, are rather well understood for the Phanerozoic and less well for the Vendian and Late Riphean. Occasionally, as is to be shown below, these are discernible in older strata as well. The spectrum of climatic oscillations has been rather broad, from several tens of years to hundreds of million years. Oscillations of various periods were superimposed on each other (Figure 3). These circumstances and the roughness of many of the age attributions restrain the precision of determination of the oscillation periodicity. Nonetheless, paleoclimate curves plotted using different techniques [Chumakov, 1993b; Douglas and Woodruff, 1981; Fot'janova and Serova, 1994; Zakharov, 1992; and many others], as well as spectral [Imbrie et al., 1984, etc.] and spectral-temporal diagrams [Chumakov and Oleinik, 2001] usually show oscillations of several ranks and their groups readily enough. This implies that the periods of many oscillations differed appreciably from one another and that one can identify oscillations of several groups, whose mean durations differed by a factor of two or more and, at times, almost an order of magnitude. I will discuss, starting with the major ones, those periodic oscillations that can be recognized using geologic methods and can be resolved on geologic time scales. It is convenient to class climatic oscillations into the following five groups [Chumakov, 1993b; 1995a]: ultralong-term, lasting a few hundreds of million years; long-term, lasting several million to a few tens of million years; medium-term, lasting many hundreds of thousand to a few million years, short-term (or Milankovitch), lasting a few tens to hundreds of thousand years, and, finally, ultrashort-term, lasting thousands of years or less.

2.1. Ultralong-term climatic oscillations. The notion of large-scale climatic periodicity has long been in circulation. Among the first to propose it were Holmes [1937, Umbgrove [1947], and Lungersgauzen [1956], who drew on the distribution of ice ages in geologic history. In establishing periodicity, these workers were compelled to largely 
rely on their intuition because of poor data coverage and scanty radiometric dating of past glaciations. They estimated the duration of climatic (glacial) cycles between 250 and 190-200 m.y., respectively. Later on, values of 300 m.y. [Keller, 1972], 300-1200 m.y. [Avdeev, 1973], 280-400 m.y. [Steiner, 1978], 217 m.y. [Zakoldaev, 1991], and 215 m.y. [Yasmanov, 1993] were advanced. In the last cases, as in a number of previous ones, the length and age of climatic periods were constrained using incomplete and partially obsolete paleoclimatic and geochronologic data. Furthermore, these data were selected and interpreted rather arbitrarily, mostly with overmuch reverence for the span of the modern galactic year (synodic or anomalistic) or based on the span of past galactic years, very conjecturally evaluated. Note that even the current galactic year is estimated by astronomers very roughly, between 180 and 300 m.y. A purely inductive approach based on solid paleoclimatic facts appears therefore more productive in establishing long-term climatic periodicity. While assessing timespans between the most frequently cited ages of glaciation for the Late Precambrian and Phanerozoic, Williams [1975] concluded the duration of climatic cycles to have been ca. 150 m.y. Later, Frakes et al. [1992] estimated the timespans between the midpoints of cool and warm intervals in the Phanerozoic and Late Precambrian in the range 138 to 181 m.y., the average being 150 m.y. as well.

The approaches used to identify major climatic cycles and the considerable scatter in their estimated durations, as well as the multitude of factors of influence on climate, made many researchers dubious about the very existence of any major climatic periodicity whatsoever [Crowell, 1999; Harland, 1981; House, 1995]. Quite justified is the skepticism toward the attempts, at times disregarding the facts, of straightforward correlation between climatic cycles and galactic years, whose duration is not even clear yet. At the same time, skepticism toward empirically established cycles appears ungrounded. Scatter in the calculated duration of the cycles is due to the transitions from warm to cool intervals and back again having been comparatively gradual, covering tens of million years. In addition, on many occasions these transitions were poorly studied, with the result that the durations of cool and warm periods were determined quite arbitrarily and, hence, subjectively. By contrast, quantifying periodicity from extreme and quite well-dated climatic events such as glacial maxima, reduces sharply the scatter in estimated durations of major climatic periods [Chumakov, 2001a]. Let us dwell on this approach in greater detail. In the Late Riphean and Paleozoic, there existed five glacial maxima (Figures 1, 4), at times also referred to as "great" glaciations: (1) the first Late Riphean great glaciation is dated tentatively between 850 and $890 \mathrm{Ma}$; (2) the second Late Riphean one, between 740 and $750 \mathrm{Ma}$; (3) the Early Vendian, at $600 \mathrm{Ma}$; (4) the Late Ordovician, at $440 \mathrm{Ma}$; and (5) the Late Paleozoic, at $290 \mathrm{Ma}$. The last four great glaciations were 140, 160, and 150 m.y. apart in time, respectively. This approach reduced sharply the discrepancy between the periods. In fact, the discrepancies lie within the error margin of the dating methods. This makes the existence of a regular climatic periodicity between the Late Riphean and Paleozoic quite obvious. Not incon- ceivably, the timespan between the first and second Late Riphean glaciations also equals $140-150$ m.y. Then, the Paleozoic-Late Riphean interval of geologic history should comprise four major climatic cycles 140-150 m.y. long each. The last Paleozoic, Asselian-early Sakmarian glacial maximum is 290 m.y. apart in time from the next, Pleistocene one. Considering that in the middle of this timespan, in the terminal Jurassic to the initial Cretaceous, evidence of cooling and locally even of seasonal ice rafting has been recorded [Frakes et al., 1992], discernible are two more Meso-Cenozoic climatic cycles, 140-150 m.y. long each. Mean durations of these five (and, including the first Late Riphean one, possibly six) climatic cycles were ca. 150 m.y. The existence of cycles of such duration is further supported by the spectral and spectral-temporal analysis of the time series of semiquantitative paleoclimatic data for the Late Riphean and Phanerozoic [Chumakov and Oleinik, 2001].

Along with the distinct 150-m.y. cycles, still larger, albeit less clearly pronounced periods are detected. Starting in the Vendian, every second glaciation among the "great" ones has had a somewhat larger scale than the previous one. For this reason, the largest glaciations (Pleistocene, Late Paleozoic, and Vendian) make two cycles lasting ca. 300 m.y. Climatic cycles 150 and 300 m.y. long were grouped into ultralong-term oscillations [Chumakov, 1993b, 1995a]. These oscillations governed the main climate changes in the Phanerozoic, Vendian, and Late Riphean, which is corroborated by comparing spectral and spectral-temporal diagrams for the time series of global temperatures and for the time series of glacial events [Chumakov and Oleinik, 2001].

\subsection{The nature of ultralong-term climatic oscil-} lations. Causes of ultralong-term climatic oscillations, especially of the "great" glaciations, have long been the focus of debate and of numerous hypotheses. Schwarzbach [1974] estimated the number of such hypotheses published in scientific literature to have reached 60 by the year 1970 . In the past three decades, a further of at least 10 or 15 new hypotheses and some 20 to 30 updated versions of the old ones have been put forward. The total number of the current hypotheses on the causes of ultralong-term climatic oscillations is, thus, nearing one hundred. Apparently, each and every speculation possible on this point, whether conceivable or not, has been advanced. Among the inconceivable ones, I place, in particular, those hypotheses that are based on postulated extraterrestrial processes that have not been validated or studied by astronomical methods. Most such hypotheses elude verification by means of geologic data. The rest of the hypotheses draw on real geologic and extraterrestrial processes, most of which doubtless bear, in one way or another, on climate. Currently, it is of a paramount importance to identify among these processes those of the greatest climatic import and those whose role is not decisive. To this end, we should examine how closely the most popular of these hypotheses are consistent with geologic facts.

The galactic year. As noted above, many researchers have been trying, in one way or another, to tie the "great" glaciation cycles in with the galactic year [Holmes, 1937; Keller, 1972; Lungersgauzen, 1956; Steiner, 1978; Umbgrove, 1947; Yasmanov, 1993; Zakoldaev, 1991; etc.] or with the galactic 


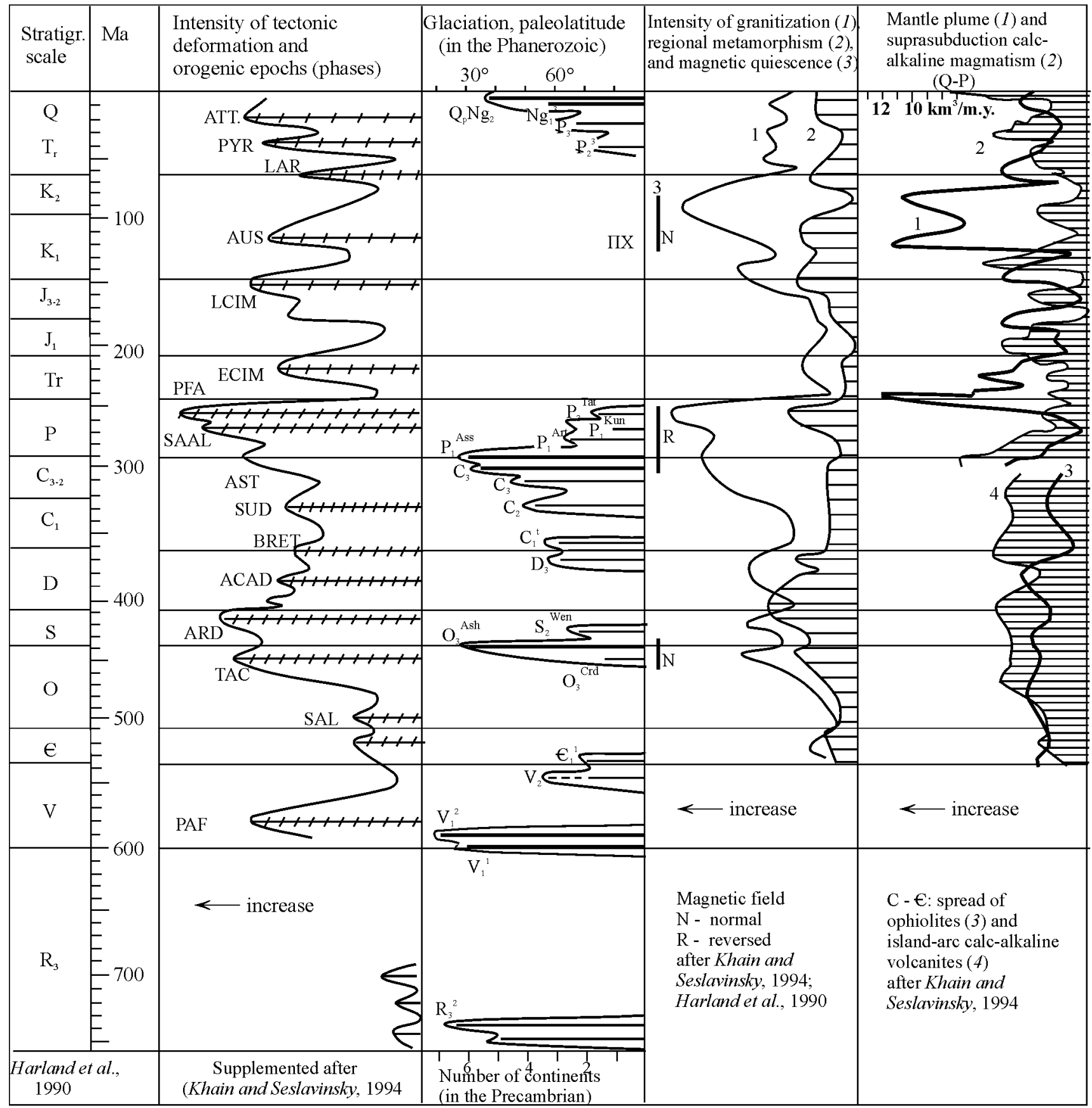

Figure 4. Periodicity of the largest ("great") glaciations and correlation of glacial periods to the intensities of some tectonic, volcanic, and metamorphic processes [Chumakov, 2001a]. Geologic time scale, modified after [Harland et al., 1990]. Intensity of tectonic deformations, epochs (phases) of tectogenesis, granitization, metamorphism, development of ophiolites and calc-alkaline volcanites in the C-Cm (after [Khain and Seslavinsky, 1994]), mantle-plume and suprasubduction magmatisms in the Q-P (after [Dobretsov, 1999]). Epochs (phases) of tectogenesis: ATT - Attic, PYR - Pyrenean, LAR - Laramian, AUS - Austrian, LCIM - Late Cimmerian, ECIM - Early Cimmerian, PFA - Pfalzian, SAAL - Saalian, AST - Asturian, SUD - Sudetic, BRET - Bretonian, ACAD - Acadian, ARD - Ardennian, TAC - Taconian, SAL - Salairian, PAF - Pan-African. Glaciations: Solid horizontal lines, glacial epochs (glacioepochs) and their ages. The length of the lines is proportionate to the maximum spread of glaciations in a given epoch (in the Phanerozoic, to paleolatitudes, and in the Precambrian, to the number of continents). Line outlining glacioepochs shows glacial periods (glacioperiods). MC - Mesozoic cooling (modified after [Chumakov, 2001a]). 
half-year [Frakes et al., 1992; Williams, 1975]. The way in which the position of the Solar System on the galactic orbit bears on Earth climate either remains beyond the scope of the authors of these hypotheses or is explained by them in the most general terms, invoking spatially variable permeability of the Galaxy to solar radiation. Emphasis is usually made on similar durations of climatic cycles and the galactic year. As shown above, however, there is no similarity between the durations of the galactic year and of principal climatic cycles. The great glaciation cycles last 150 m.y., a value much smaller than the available estimates for the galactic year. As for the comparison with the galactic halfyear, it does not stand to reason unless one makes additional assumptions [Williams, 1975] that are hard to verify and that, moreover, differ essentially from those proposed by other authors [House, 1995].

High-latitude position of continents. It had long been considered [Caputo and Crowell, 1985; and others], and is still believed by many, that the main cause of glaciations was near-polar position of the continents. However, Phanerozoic history witnessed recurrent situations where continents occurred in polar regions or even at the Pole without glaciations occurring on the Earth. For example, in the Late Silurian and Early-Middle Devonian, near or at the South Pole there existed vast Gondwanan landmasses, but no glaciation took place. On the contrary, it was very warm, salt deposits and redbeds extending into high latitudes. A similar setup existed in the Mesozoic. Antarctica had been situated at high polar latitudes since the Triassic. By the Santonian, Antarctica had traveled to the Pole, but ice sheets on it did not appear until the Late or even Middle Eocene, i.e., more than 45 m.y. later. More telling still are those cases where at a polar location of a continent, glaciation that had existed on it came to an end. Relevant examples are provided by the Middle Silurian, Late Devonian-early Tournaisian, and Permian glaciations: all three terminated while the south part of Gondwana was situated at high latitudes or at the Pole. In Asselian-early Sakmarian time of the Early Permian, in particular, a vast ice sheet covered three-quarters of Gondwana, whose south part was located at the Pole. During the Permian, at a nearly identical position of Gondwana, the glacial belt degraded, and by the Indian age of the Early Triassic the climate had become temperate and warm temperate [Chumakov and Zharkov, 2001]. The above examples suggest that, although high-latitude continents were prerequisite for ice sheets to form on, and, apparently, promoted their formation, such continents alone were insufficient for the initiation or even maintenance of glaciations then already in existence.

The role of oceanic circulation. A similar conclusion can be made regarding oceanic circulation. The oceanic circulation system is known to have been defined by the configuration and latitudinal position of seas and continents, these variables remaining basically unchanged in the all the cases of inception and cessation of glaciations just mentioned.

Remarkably, even the most striking examples where new seaways opened and cold currents, such as, e.g., the southern circumpolar West Wind Current, formed to block heat exchange, cannot all be held responsible for the origin of glaciations. On the Antarctica shelf, glacial-marine deposits indicative of the onset of extensive glaciation appeared in the Late or Middle Eocene [Ehrmann et al., 1992; Wise et al., 1991]. Therefore, although the Cenozoic glaciation started much later than Antarctica had migrated into the polar region, still its onset predated perceptibly the formation, at the Eocene/Oligocene boundary, of the southern circumpolar current, which ensued from the opening of the Drake and Tasman passages. This current is believed by many workers to have triggered the Late Cenozoic glaciation on Earth or, at least, in Antarctica, but it appears to merely have amplified the glaciation that had started earlier.

Greenhouse gases. A great or even decisive part in climate changes is currently attributed to variations in atmosphic contents of greenhouse gases, especially $\mathrm{CO}_{2}$. Cooling events are associated with decreases, and warming events with increases of the concentration of this gas. However, the role of $\mathrm{CO}_{2}$ in climate changes cannot be now interpreted so unequivocally as formerly.

The challenge lies in that climates and atmospheric $\mathrm{CO}_{2}$ contents are very tightly linked by positive feedbacks, such that it is not quite clear whether climate changes began with changes in atmospheric $\mathrm{CO}_{2}$ concentration or whether, vice versa, climate changes brought about changes in $\mathrm{CO}_{2}$ concentration. The latter may have occurred due to degassing of oceans in times of warming and to additional dissolution of $\mathrm{CO}_{2}$ in the cold ocean (psychrosphere) in the course of cooling events. That climate changes bear on $\mathrm{CO}_{2}$ concentration, is supported by Antarctic ice core evidence suggesting that " $\mathrm{CO}_{2}$ content drops following a temperature decrease with a lag of several thousand years..." [Kotlyakov and Lorius, 2000]. Besides, recent data show that increases of ocean water temperature predated increases of atmospheric $\mathrm{CO}_{2}$ content with a few months' lag [Krasilov, 1992]. Comparing climate history with atmospheric $\mathrm{CO}_{2}$ concentration curves, as reconstructed by different workers [Berner and Kothavala, 2001; Budyko et al., 1985], shows that glaciations may have occurred at high, and warming events at comparatively low $\mathrm{CO}_{2}$ contents. The Late Devonian glaciation, e.g., took place at an atmospheric $\mathrm{CO}_{2}$ concentration that was at least 3 times, but more likely 7 times that of the glacial Pleistocene, and the same as in the very warm, non-glacial Middle Cretaceous [Berner and Kothavala, 2001]. Based on the same data, the Middle Silurian, Late Ordovician, and Early Cambrian glaciations occurred at even higher atmospheric $\mathrm{CO}_{2}$ concentrations (at least 7 , but more likely 16 times that in the Pleistocene). Therefore, either the reconstructed past atmospheric $\mathrm{CO}_{2}$ concentrations are entirely spurious, or the notion of the decisive role of $\mathrm{CO}_{2}$ in climate changes should be deemed erroneous. Hence, albeit it is beyond doubt that atmospheric $\mathrm{CO}_{2}$ deficit lowers, whereas $\mathrm{CO}_{2}$ excess raises the Earth's heat balance, the cited data put to question the determinant role of $\mathrm{CO}_{2}$ in climate changes and, in particular, in the initiation of glaciation. Apparently, it is more sound to assume that $\mathrm{CO}_{2}$ deficit in the atmosphere is not so much a cause of glaciations as their effect, produced by $\mathrm{CO}_{2}$ dissolution in the psychrosphere, and leading to expansion of glaciation. Since the behavior of methane in the latest glacial and interglacial epochs is similar to that of $\mathrm{CO}_{2}$ [Kotlyakov and Lorius, 2000], this assumption might apply to methane as well. 
Supercontinents. It has been opined that glaciations occurred in the epochs of existence of supercontinents [Bozhko, 2001; Veevers, 1990]. This agrees poorly with the periodicity of Phanerozoic glaciations and with the continuous existence of supercontinents in this eon. Judging from the latest reconstructions [Golonka and Ford, 2000; Golonka et al., 1994], supercontinents have been typical of the entire Phanerozoic. The supercontinent of Gondwana existed throughout the Early and Middle Paleozoic. From the Late Paleozoic to the Early Jurassic, there existed a yet larger supercontinent, Pangea. Between the Middle Jurassic and Early Cretaceous, there were two supercontinents, Gondwana and Laurasia. Laurasia persisted into the beginning of the Paleogene. From the initial Paleogene on to the present, the supercontinent of Eurasia has been in existence. If the supercontinent concept were restricted to such entities only that bring together all the continents on the planet, i.e., to Pangeas [Veevers, 1990], then the hypothesis in point would be at odds with the presence of glaciations in the Early Cambrian, Late Ordovician-Middle Silurian, Late Devonian-early Tournaisian, and Pleistocene.

Tectogenesis and orogeny. In great vogue are those hypotheses coupling in one way or another glaciations to tectogenesis, mountain building, or continental uplifting. Such a hypothesis was first formulated almost 100 ago by R. Ramsey. Its latest version was put forward by Ruddiman and coauthors [Ruddiman, 1997] and by other researchers. These hypotheses attribute cooling to the influence of newly formed mountains and uplands, to the inception of mountain glaciers triggering further growth of ice sheets by positive feedback, and to heat and moisture exchange being hampered or transformed by mountain edifices. Currently, an important cause of cooling is not infrequently seen in orogeny-related invigoration of weathering processes, with the resultant consumption of considerable amounts of $\mathrm{CO}_{2}$ from the atmosphere. Direct correlations were often made between glaciations and tectonic cycles: the Early Vendian Laplandian (or Varangerian) glaciations were linked to the Pan-African orogeny; Early Paleozoic glaciations, to the Caledonian orogeny; Late Paleozoic glaciations, to the Hercynian orogeny; and Late Cenozoic ones, to the Alpine orogeny.

In recent years, on the one hand, the age and scales of Phanerozoic and Late Precambrian glaciations have been essentially constrained, and on the other, the scale of tectonic, magmatic, and metamorphic processes in the Phanerozoic has been estimated at semiquantitative and quantitative levels [Dobretsov, 1999; Khain and Seslavinsky, 1994]. This has afforded a much more refined correlation between glaciations and tectonic events than previously [Chumakov, 2001a]. Such correlations show that, although in terms of their duration glacial cycles were rather close to principal tectonic cycles, no direct correlation exists between them. Glacial cycles did not coincide with tectonic ones in phase, glacial maxima (great glaciations) predating the most intensive, final phases of tectonic cycles (Figure 4). Moreover, during the culminations of tectogenesis, glaciations ceased or started to degrade quickly. Such a succession of events is thrice distinctly recorded in geologic history. The Laplandian (Early Vendian) glaciation preceded the Pan-African phase, and the Early Paleozoic came before the main, Ardennian phase of the Caledonian cycle, the Ardennian phase itself coinciding with the termination of this glaciation. The Late Paleozoic glaciation culminated ca. 40 m.y. prior to the strongest, Saalic and Pfalzian, phases of the Hercynian orogeny, which were accompanied by a rapid degradation and cessation of the Late Paleozoic ice age. It is common knowledge that orogenic climaxes and intervals that followed immediately were associated with the principal mountain building pulses, massive granite emplacement, and regional metamorphism. It is more likely therefore that principal phases of tectogenesis and mountain building cause the degradation and cessation of glaciations, and not their inception. Glaciations were clearly initiated by some other processes.

The character of volcanism. As is seen from Figure 4, a certain correlation existed between glaciations and volcanic events. Record shows the coincidence of Lower, Middle, and Upper Paleozoic and Late Cenozoic glaciations with pulses of suprasubduction volcanism. These coincidences imply that in times of the rise and relative dominance of this type of volcanism (which largely involves explosive eruptions) atmospheric transparency decreased, the Earth's surface temperature dropped, and volcanic winters set in. The likelihood of quick and intensive cooling due to reduction in atmospheric transparency has been shown by mathematical simulation of the nuclear winter. A number of historically and geologically recorded cases where cooling was induced by major explosive eruptions are known to exist. Observations from the past 150 years show that even single explosive eruptions lowered perceptibly the temperature in an entire hemisphere for years [Mitchell, 1970]. A series of successive eruptions or even single very large explosive eruptions may evidently have led to volcanic winters. Thus, the huge explosive eruption of the Toba volcano in the Late Pleistocene coincided with the onset of the Valdai glaciation [Rampino and Self, 1992]. The beginning of the large glaciation of the Northern Hemisphere in the terminal Pliocene (ca. 2.65 Ma BP) correlates with a dramatic increase of explosive volcanism in the North Pacific. Both events are recorded by a sharp increase in the content of volcanic and iceberg-rafted material in sediments of this region and by the onset of extensive glaciation on land [Prueher and Rea, 2001].

Volcanic winters must have been the climatic pulses that triggered glaciations. Once incepted, ice sheets, owing to numerous strong positive feedbacks in the biosphere (Figure 5), not only became stable, but also acquired the ability to expand. Needless to say, subsequent episodes of explosive volcanism could have maintained and sped up these processes.

The waning of island-arc volcanism during principal tectonic phases led to an increase in atmospheric transparency and to growth of the Earth's surface heat balance. Erosion and regional metamorphism within orogens accompanying the principal tectonic phases resulted in oxidation of dispersed organic and carbonaceous matters and in their deposition in sedimentary piles. Besides, massive granitization and regional metamorphism caused decomposition of carbonates (dedolomitization and decarbonatization) in mixed carbonate-terrigenous rocks [Mason, 1978; Winkler, 1976]. The $\mathrm{CO}_{2}$ thus formed was supplied to the atmosphere, to induce further warming. The growth of greenhous gases 


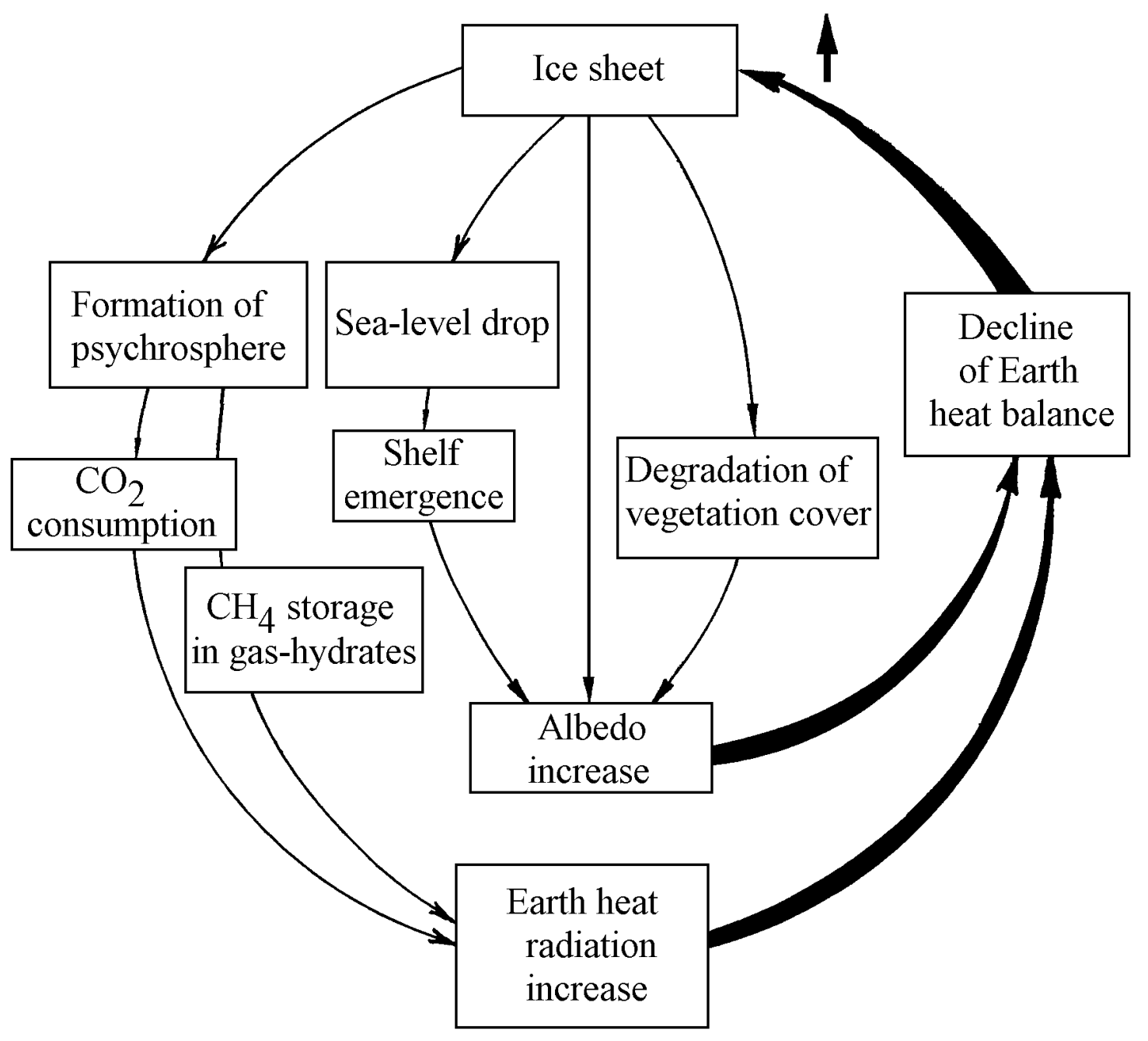

Figure 5. Some positive biospheric feedbacks of glaciation.

content in the atmosphere was often promoted by a concomitant increase of mantle plume magmatism. Simultaneously, oceans warmed and degassed, gas-hydrate pools were decomposed, and evaporation and aqueous vapor content of the atmosphere increased. Jointly, all these processes added to the greenhouse effect and, alongside an increase in atmospheric transparency, led to considerable warming and rapid deglaciation.

Impact events. The immediate climatic effects of major impact events may have approximated volcanic winters, although, according to nuclear winter modeling, these effects must have been comparatively short-lived (several months to just over one year). Besides, major impact events occurred seldom. Evidently, they might have caused temporary cooling, but they were insufficient to form perennial large-size ice sheets on Earth. At any rate, several very large impact events that occurred in the Triassic, Jurassic, Cretaceous, and at the Cretaceous/Paleogene transition were not accompanied by glaciation.

Therefore, among the inferred causes of ice ages (and ultralong-term climatic oscillations as a whole), not all were of equal influence on climate. The current degree of stratigraphic understanding affords detailed correlations of ice ages with geologic events in four cases: for the Ordovician-Silurian, Devonian-Early Carboniferous, Permo-Carboniferous, and Late Cenozoic glaciations. In all these cases, onset of glaciation coincided with a peak of suprasubduction volcanism. In all three completed glacial periods, their cessation coincided with the waning of suprasubduction volcanism, with major orogenic pulses, and, not infrequently, with pulses of mantle plume volcanism, which was especially massive at the end of the Permian. The correlation between glaciation and the listed endogenetic events (unlike the other causes discussed above) is established in all the cases-i.e., it equals $100 \%$. This suggests that pulses of suprasubduction volcanism were necessary and sufficient, i.e., chief causes of the onset of glacial periods. Accordingly, deglaciations resulted from the waning of suprasubduction volcanism, from the processes that accompanied orogenic maxima, and from the pulses of mantle plume volcanism. The intensity of the latter varied in counterphase to suprasubduction volcanism [Dobretsov, 1999]. 
The rest of the geologic processes and events here discussed also influenced climate in one degree or another, but they were far from always being accompanied by glaciations. This allows regarding them as necessary but insufficient conditions for glaciation to occur (which applies, e.g., to the polar position of continents) or as conditions promoting the inception, maintenance, or growth of glaciations, but insufficient and not indispensable to their inception or cessation. The paleoclimatologic data at hand give grounds to believe that even a combined effect of several synchronous "insufficient" causative events could not have triggered glaciation (Table 1).

The great glaciations were the peaks of glacial periods (glacioperiods; [Chumakov, 1985]). The latter ranged widely in duration from ca. $10-15$ to 78 m.y., averaging ca. 27 m.y. in the Phanerozoic to the Late Riphean. Glacial periods were separated by longer non-glacial ones (thermoperiods; [Chumakov, 1985]), which lasted 30 to 205 m.y., averaging ca. 95 m.y., in the Phanerozoic to Late Riphean. Climatic cycles comprised of alternating glacial periods (including the Middle Mesozoic cooling) and thermoperiods range from 55 to $180 \mathrm{~m} . \mathrm{y}$. In view of the rather strict periodicity of glacial maxima, the time-irregularity of climatic divisions associated with them presents a problem requiring special analysis and discussion. At this point it can only be assumed that this might have been due to various combinations of paleogeographic, geochemical, and geodynamic factors that accompanied glaciations and that exerted certain influences on their stability and scale, but that were insufficient for their inception or cessation.

2.3. Long-term climatic oscillations. The above glacial periods were comprised of separate shorter-term events - glacial and interglacial epochs (glacio- and thermoepochs; [Chumakov, 1985])-lasting between several and 10-15 m.y. each (Figures 1, 2). The mean duration of these epochs can be assessed roughly from those glacial sequences with well-dated successions of several climatic epochs. Such sequences are established in the Early Paleozoic of West Africa [Chumakov, 1993b], in the Late Paleozoic of Eastern Australia and South Africa [Chumakov, 1993b, 1995a], and in the Cenozoic of Eastern Asia [Fot'janova and Serova, 1994; Velichko et al., 1994; etc.]. Alternating, though less contrasting, climatic epochs of similar duration, which can be termed thermoepochs and semi-thermal epochs, are also established in non-glacial intervals of the Phanerozoic: in the Jurassic of Western Siberia [Velichko et al., 1994] and in the Late Cretaceous of Northeast Asia [German, 1993; Krasheninnikov et al., 1990], the Indian Ocean [Clarke and Jenkyns, 1999], the Falkland Plateau [Krasheninnikov et al., 1990], and Antarctica [Dingle and Lavelle, 1998]. Climatic cycles comprised of contiguous mutually opposing climatic epochs are called long-term cycles. Their duration in the Phanerozoic is estimated to average 15-30 m.y.

Long-term climatic oscillations apparently had the same underlying causes as ultralong-term ones. Against the background of principal tectonic and climatic cycles discussed above, the intensities of subduction-related and mantleplume volcanisms also varied in counterphase to one another at periods of a few tens of million years [Dobretsov, 1999; Do- bretsov and Kirdyashkin, 1998]. For this reason, long-term climatic oscillations can also be attributed to these variations in the intensity and character of the Earth's magmatic activity [Chumakov, 2001a]. The lack of glaciation during non-glacial intervals, in all likelihood, was due to relative prevalence of mantle-plume volcanism and to massive development of regional metamorphic processes. At any rate, this explanation suggests itself while analyzing the dynamics of principal types of volcanism and metamorphism during the Siberian thermoera ("Mesozoic" non-glacial interval; [Chumakov, 1985, 1992]). The total predominance of mantle plume volcanism and very broad development of regional metamorphism processes in this interval can be seen from Figure 4.

2.4. Medium-term climatic oscillations. In the last decade, it has been established that climatic epochs were not uniform and in turn consisted of alternating cooler and warmer intervals. Because these intervals were subordinate to the climatic epochs, in compliance with the commonly accepted system it would be reasonable to call them climatic ages. Within glacial epochs, they can be termed glacial ages (glacioages) and thermal ages (thermoages) and within nonglacial epochs, semi-thermal ages and thermal ages, respectively. The climatic ages usually lasted many hundreds of thousand years to a few million years, whereas the cycles comprised of alternating cool and warm ages lasted from one million to ten million years.

Medium-term climatic oscillations had long been largely disregarded. On most climatic curves they were smoothed out, and in paleoclimatic reconstructions and numerical models, ignored. However, they account for the bulk (over $50 \%$ ) of the number of climatic oscillations larger than $\mathrm{Mi}$ lankovitch ones [Chumakov, 1995a]. Medium-term oscillations may have been associated with very considerable temperature oscillations, which, e.g., in the Late Cretaceous of Far East are estimated at $10^{\circ}-12^{\circ} \mathrm{C}$ [Zakharov et al., 1999a], and in the Oligocene and Early Miocene for deep oceanic waters, at $3-6^{\circ} \mathrm{C}$ [Zachos et al., 2001]. In the Greenland and Norwegian seas, Pleistocene ice rafting episodes were associated with the minima of medium-term oscillations [Velichko and Nechaev, 1999].

The causes of medium-term climatic oscillations are not yet clear enough. In particular, the longest-term variations in the eccentricity of the Earth orbit have been invoked [Herbert et al., 1999]. Noteworthy is also the similarity of the periods of medium-term climatic oscillations to those of highfrequency eustatic sea-level changes.

2.5. Short-term climatic oscillations. Short-term, or Milankovitch [Imbrie et al., 1984] climatic oscillations, lasting a few tens to hundreds of thousand years, have long been known in the Pleistocene, because at high and middle latitudes they led to alternating glacial and interglacial ages and glacial stadials and interstadials. Their extent was global, and they were pronounced, albeit in a different and not so sharp fashion, in other latitudinal belts and in all the subsystems of the biosphere. On land, outside the reach of Pleistocene inland glaciations, short-term climatic oscillations are readily established from loess paleosol profiles [Dodonov, 2001; Zubakov, 1986], from the sediment record 
in lakes [Karabanov et al., 2000; Lowenstein et al., 1999], from successions of alternating humid and more or less arid environments, and from the turnover of floral assemblages [Dupont et al., 2000; van der Kaars et al., 1995]. In seas and oceans, these oscillations induced changes in the temperature of surface waters [Velichko and Nechaev, 1999] and deep waters [Chapman and Shackleton, 1999], sea-level oscillations and essential changes in depositional processes [ Lisitsyn, 1988], turnover of faunal assemblages [Barash et al., 1989; etc.], oscillations of primary bioproductivity [Beaufort et al., 1997], variations in isotope compositions of oxygen [Imbrie et al., 1984] and carbon, as well as other sedimentary, biotic, and geochemical events. In the atmosphere, short-term climatic oscillations, as established from gas admixtures in glacial cores, were accompanied by changes in greenhouse gases and dust contents and in isotope compositions of oxygen and hydrogen [Kotlyakov and Lorius, 2000].

Short-term climatic oscillations had long been regarded as being characteristic of ice ages alone [Velichko, 1987; Woldstedt, 1954]. It has been shown, however, that these oscillations, variously manifested, constituted the dominant type of climatic changes at least through all of the Phanerozoic, during glacial and non-glacial ages alike. Listed below are only a few of the many publications on pre-Pleistocene short-term climatic oscillations: in the Pliocene [Raymo, 1992; Zubakov and Borzenkova, 1983; and many others], Miocene and Paleogene [Zachos et al., 2001], Cretaceous [Larson et al., 1993; Mutterlose and Ruffell, 1999], Jurassic [Waterhouse, 1999], Permian [Anderson and Dean, 1995], Carboniferous [Miller and Eriksson, 1999; Weedon and Read, 1995], Devonian [Wu et al., 2001], Silurian and Ordovician [Williams, 1991], and in the Ordovician [Sutcliffe et al., 2000].

In the wake of the works of J. Adhemar, J. Croll, and, especially, M. Milankovitch, many geoscientists started connecting Pleistocene glacial events to variations in orbital parameters and in the angle of tilt of the Earth's axis of rotation. The studies of oceanic sediments in the 1970s are known to have shown that variations of oxygen isotope composition in carbonates, reflecting the ice volume on our planet, correlate tightly with astronomical cycles of 19, 23, 41, and, particularly, 100 ka [Imbrie et al., 1984]. Paleotemperature and a number of other climatologically significant parameters were established to have varied at closely similar periodicities, as inferred from geochemical evidence on glacial cores from Greenland and Antarctica [Kotlyakov and Lorius, 2000]. Besides, the most complete sequences of glacial and non-glacial deposits preserve record of cycles lasting 400-410 ka [Herbert et al., 1999]. These data, along with numerous isotope and other datings for interglacial deposits, offer convincing proofs of orbital forcing for short-term oscillations. Rather weighty additional evidence in favor of astronomical causes for short-term climatic oscillations is the fact that they occurred throughout the Phanerozoic, irrespective of repeated changes in geologic, geographic, climatic, and biotic situations on Earth.

2.6. Ultrashort-term climatic oscillations. These oscillations, lasting thousands, many hundred, a few hundred, and tens of years or less, are pinpointed using instrumental observations, as well as historical, archeological, den- drometric, glaciogeologic, and geologic data, mainly in the Holocene and Late Pleistocene [Bianchi and McCave, 1999; Broecker and Denton, 1989; Kotlyakov and Lorius, 2000; Lee and Slowey, 1999; and many others]. A considerable part of ultrashort-term oscillations show a certain degree of correlation with solar activity. In particular, radiocarbon studies in tree growth rings have resolved cycles of appreciably increased solar activity lasting ca. 2400, 200, and 90 years. The first two cycles roughly coincide in duration and phase with Holocene climatic cycles [Dergachev, 1994]. In older deposits, ultrashort-term cyclicities are detected on rare occasions only (e.g., the 200-year cycle; [Anderson and Dean, 1995]).

2.7. Weather oscillations. By definition, climate is characterized by multi-year mean meteorologic parameters. Changes of these parameters over periods of less than 40 years are conventionally classed as weather oscillations. The latter are known to be dominated by annual (seasonal) and diurnal oscillations. In addition, a number of multi-year cycles are observed. Some of these are also associated with solar activity variations. In certain cases, seasonal [Chambers et al., 2000; and some others] and multi-year climatic cycles are detectable with a certain degree of probability in ancient strata as well.

2.8. Climatic oscillations in the Precambrian. The poor resolving ability of radiometric and biostratigraphic methods in the Precambrian and the paucity of reliable radiometric measurements hamper direct quantification of the periodicity of Precambrian climatic oscillations in most cases. Nonetheless, counterparts of the largest-scale Phanerozoic climatic oscillations are also discernible, with a certain degree of confidence, in the Proterozoic as well. The presence in the Vendian-Late Riphean of two ultralong-term climatic cycles ca. 140-150 m.y. long is beyond all doubt (Figure 1). Grounds for establishing subordinate, smallerscale cycles are given by the alternation of glacial and interglacial deposits observable in those most complete sequences that correspond to glacial phases of the ultralong-term Precambrian cycles. These sequences, in terms of sedimentary facies, facies combinations, and facies thicknesses, are at times indistinguishable from Phanerozoic glacial sequences, so that at the pioneering stages of research they were occasionally misattributed to the Phanerozoic; e.g., Vendian glacial sequences of Middle and Central Asia, to the PermoCarboniferous, and Paleo-Proterozoic Griquatown diamictites, to the Cambrian or Eo-Cambrian [Gevers and Beets, 1940].

Let us scrutinize certain characteristic Precambrian glacial sequences from the standpoint of climatic oscillations. The Vilchitsy Group, Belarus, deposited in the Laplandian (Varangerian) ice age, consists of two formations - the upper, glacial Glussk Formation and its underlying Blon' Formation. The lower part of the latter is composed of glacial deposits, and its upper part, of interglacial sandstone and sandy dolomite. The Glussk Formation, where stratigraphically complete, contains three tillite members separated by banded clays with dropstones and well-sorted, apparently fluvial sands with thin clayey intercalations, sporadic ripple marks, and desiccation cracks. The tops of these inter-tillite 
members display glaciotectonic deformations. It is reasonable to assume that the Glussk and lower Blon' Formations correspond to glaciations, and the sequence that separates them, to the interglacial epoch of the Laplandian ice age. Then, the combination of mutually opposing epochs represents long-term climatic oscillations. A similar composite but overall tripartite succession is exhibited by the stratotypal section of the Laplandian glacial period in northern Norway, by the sequences of Spitsbergen [Chumakov, 1978] and eastern Greenland [Hambrey and Spencer, 1987], and by one of the most complete sections of the Laplandian ice age in the Middle Urals [Chumakov, 1998].

The alternation of tillite units and lacustrine and fluvial deposits within the Glussk Formation suggests three episodes of advance and recession of glaciers. These events may correspond to glacial and interglacial ages, and their combination, to medium-term climatic oscillations. Similar climatic events can also be more or less confidently deciphered in the rest of the Laplandian sequences listed above.

The most complete sections of the first and second Late Riphean glacial periods commonly also consist of alternating glacial and interglacial members, suggestive of the existence of climatic epochs. Thus, deposits of the last Late Riphean (Early Sinian) ice age in the People's Republic of China are comprised of two glacial formations, the lower Changan and the upper Nantuo, with the interglacial Liantuo, or Fulu Formation, in-between [Hambrey et al., 1981]. The Nantuo Formation in turn contains two tillite horizons. Deposits of the last Late Riphean glaciation in southern Australia (Sturtian; [Preiss, 1987]) and in the western USA (Pocatello and Perry Canyon Groups and their correlatives; [Link et al., 1994]) also contain two major glacial episodes that can be interpreted as glacial epochs consisting of shorter-term glacial events. The same holds true of the two glacial subhorizons of the Grand Conglomerate, Katanga [Hambrey et al., 1981]. The latter evidently belongs to the deposits of the first Late Riphean ice age.

Traces of major climatic oscillations are to be found in the Early Proterozoic as well. As mentioned above, the Canadian glacial period lasted ca. 100 m.y., and hence it is reasonable that the three glacial formations that are subordinate to the Huronian Supergroup, Canada, should be viewed as corresponding to glacial epochs. Each of the glacial formations has a rather complex structure, and the Gowganda Formation is divided into three major glacial members, 80 to $150 \mathrm{~m}$ thick, consisting of several nonuniform tillite beds separated by unconformities, shales, and sandstones [Young, 1970]. The events corresponding to these members can well be viewed as counterparts of glacial ages, and their alternation with interglacial deposits, as medium-term climatic oscillations. A rather complex cyclicity is also recorded in the Early Proterozoic Griquatown glacial horizon (the Makganyene Diamictite Formation), where drilling recovered six glacial members 8 to $95 \mathrm{~m}$ thick separated by interglacial members of sandstone, ferruginous carbonate, and limestone ranging from 4 to $16 \mathrm{~m}$ in thickness [Visser, 1981]. A succession of several alternating beds of glacial and interglacial deposits is also observed in the Late Archean glacial deposits of the Republic of South Africa. Thus, in the glacial horizon of the Mozaan Group, four glacial beds ranging in thickness from a few to $20-30 \mathrm{~m}$ are separated by members of sandstone and shale several tens of meters thick each [Young et al., 1998]. Therefore, it is very likely that climatic oscillations of the first ranks: ultralong-term, long-term, and, evidently, medium-term - occurred not only in the Phanerozoic, but also in glacial intervals of the Precambrian. Apparently, shorter-term oscillations also took place in the Precambrian.

To summarize the totality of data on climatic periodicity, it can be ascertained that in the Phanerozoic and, evidently, in the Precambrian, there existed a hierarchy of climatic oscillations consisting of at least 10 to 12 ranks (Figure 6).

\section{Features of the Hierarchy of Climatic Oscillations}

3.1. Stability. The above data suggest that a complex hierarchy of climatic oscillations has existed, throughout the Phanerozoic, i.e., for more than 500 m.y., and that it has been stable enough. In the glacial intervals of the Vendian and Late Riphean, ultralong-term oscillations are recognized with confidence, long-term and medium-term ones are established with a certain caution, and those of still shorter duration are inferred. Climatic oscillations that had a similar geologic expression accompanied glacial intervals in the Early Proterozoic as well, and possibly also in the Late Archean, but estimating their rank appears to be impossible today.

The existence of a stable multi-rank hierarchy of climatic oscillations during at least the Phanerozoic provides evidence that the factors governing these oscillations were many and persistent. This offers a potential possibility of extracting individual oscillations from integrated paleoclimatic curves and identifying their causative processes based on characteristic features of the oscillations (frequency, amplitude, configuration). As demonstrated above, reconstructions of the concomitant geologic events and environments may be of a great importance to such identification.

3.2. Amplitudes of climatic oscillations. Conceivably, the amplitudes of climatic changes were the sum total of elementary oscillations of various geneses, superposed on each other. If so, the amplitudes of oscillations would have been defined by the degree of phase coherence of elementary oscillations. With minor changes, this assumption must, apparently, be valid in most cases. However, much depended on the feedbacks induced by these climatic changes in the biosphere. Negative feedbacks could have weakened, and positive feedbacks, reinforced the changes. In reality therefore things were more complex. In the Mesozoic, e.g., short-term (Milankovitch) cycles led to comparatively small climatic changes. By contrast, in the Pleistocene and Upper Paleozoic, these same cycles might have been accompanied by enormous glaciations. Such striking distinctions can be explained as follows. As a result of lasting cooling processes induced by ultralong- and long-term climatic oscillations, the axes of short-wavelength oscillations approximated the temperature threshold across which ice sheets appeared and started growing quickly [Chumakov, 1995b]. Therefore, in times of short-term (Milankovitch) 


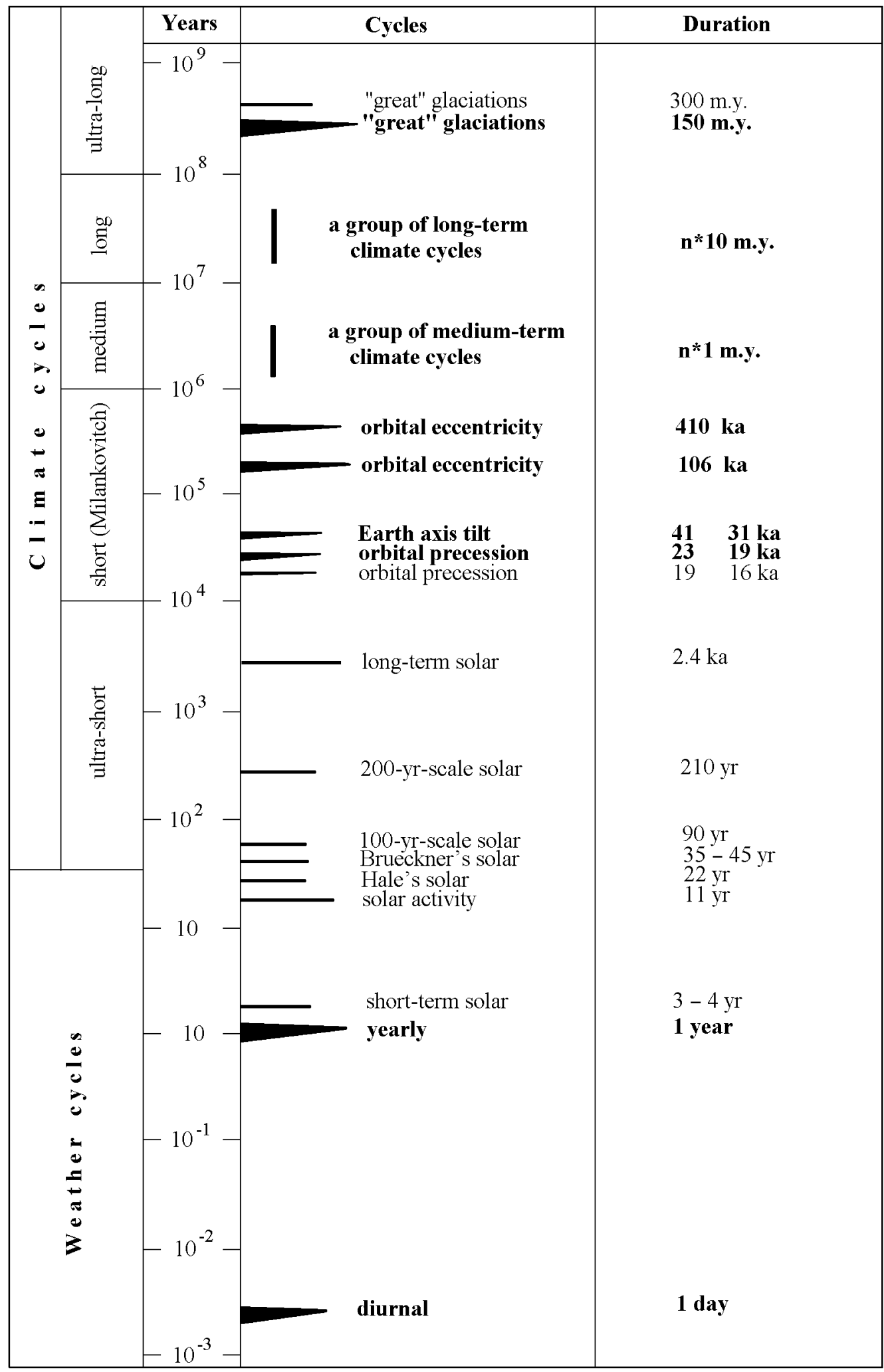

Figure 6. Hierarchy of climatic and weather cycles (bold, the most important cycles). 
cooling phases, this threshold might have been crossed. As a result, ice sheets appeared, to induce a rapid growth of albedo and other processes linked to glaciation by positive feedback (Figure 5). These processes led to further cooling and contributed strongly to the growth of the amplitude of the cooling phases of short-wavelength oscillations.

Based on these considerations, the following working hypothesis concerning the amplitude of climate changes can be proposed. In non-glacial climate, the amplitudes of minor climate changes are usually the sum total of changes induced at a given time by the elementary climate oscillations. Then, the amount of change is defined by the degree of phase coherence of the latter. Provided the resultant climatic changes are considerable, their resultant amplitude can be strongly influenced by biospheric processes coupled to these changes by feedbacks. At their extreme, positive feedbacks gave rise to a perennial glaciosphere, with a resultant drastic increase in the amplitude of oscillations.

3.3. Predominance of non-glacial climate. In terms of their duration, non-glacial periods (thermoperiods) accounted for $70 \%$ of the Phanerozoic, $78 \%$ of the last climatic stage (with periodic glaciations), and almost $90 \%$ of the second climatic stage (with episodic glaciations). In reality, however, the role of non-glacial climate in geologic history has been even greater-due to the fact that glacial events were discrete and alternated with interglacial ones at all levels, from glacial periods to glacials (glaciations s.s., or "glacials," as employed by Quaternary geologists). Hence, assuming as a first approximation that glacial and nonglacial episodes were equal in duration, the total span of glacial epochs should account for ca. $60-50 \%$ of glacial periods, depending on how many epochs there are in a period. Glacial epochs themselves consisted of glacial ages to the same extent of $60-50 \%$, the latter in turn consisting of glacials and interglacials. Judging from the temperature curves for the last $420 \mathrm{ka}$ obtained using deuterium and oxygen isotope measurements on Antarctic glacial cores [Kotlyakov and Lorius, 2000], at high latitudes glacials accounted for ca. $85 \%$ of the second half of the Pleistocene glacial age. Evidently, this was their greatest possible extent, characteristic of polar regions in times of glacial maxima. It is therefore easy to calculate that glaciations proper accounted for no more than $30 \%$ of the timespan of glacial periods and, consequently, for no more than $10 \%$ of the Phanerozoic, $7 \%$ of the last climatic stage, and $3 \%$ of the previous climatic stage. These values, based on the latest stratigraphic data, are more accurate than my own previous, higher estimates [Chumakov, 1995b].

The predominance of non-glacial climate and subordinate role of glacial climate in geologic history suggest that global temperature oscillations on the Earth occurred mainly above freezing point. In other words, the axial line of these oscillations has been located in the region of positive global temperatures. These considerations can be illustrated by the following example, which also serves to roughly estimate global temperatures on a glacial and non-glacial Earth. We live in a glacial climate; this is readily evident from the existence of large enough polar ice caps and glaciers and from the presence of a thick psychrosphere (cool ocean) on our planet. The mean global temperature at the Earth's surface is known to be ca. $+15^{\circ} \mathrm{C}$ at the present. During the last glacial maximum, it was several degrees lower, and in the non-glacial Late Cretaceous epoch, several degrees higher than the present value - i.e., throughout this timespan the mean global temperature at the Earth's surface has remained well above freezing point.

The aforementioned hypothesis of global glaciations in the Late Precambrian (see Note 4) allows for the possibility of lower, global temperatures, even below freezing point. Geologic data [Chumakov, 1992; Smith, 2001] and computer modeling of climate, carried out some years ago and lately, using more refined models, fail to validate this assumption [Poulsen et al., 2001]. This suggests that, regardless of whether glaciers appear at low latitudes on land, lowlatitude and a considerable part of middle-latitude areas in the ocean (i.e., much more than half the Earth's surface) will not be iced, even seasonally. The mean global temperature at the Earth's surface will therefore remain above $0^{\circ} \mathrm{C}$.

The temperature level about which the climate oscillated ("temperature axis") did not remain the same over time. The main factors capable of changing this level were the planet's albedo, atmospheric composition, and orbital parameters. Assumedly, the temperature threshold across which persistent glaciations appeared and non-glacial climates gave way to glacial ones did not remain unchanged, either. It depended to a certain extent on the paleogeographic situations at high and middle latitudes and on atmospheric and hydrospheric circulation systems.

3.4. The global, synchronous, and in-phase character of climatic oscillations. Approximate synchroneity of glacial periods on different continents and, consequently, their global extent arouse little doubt. This synchroneity is corroborated by paleontologic and radiometric datings. Establishing time relationships among climatic oscillations of lower ranks and between distant regions is a much more arduous exercise. It is feasible only for stratigraphically well-studied intervals of the Phanerozoic. Correlating climatic oscillations within such intervals has shown that among the shorter-term ones, there are global and regional oscillations.

Global oscillations have been synchronous and phasecoherent. This is readily established using case studies on present-day glaciers [Zakharov et al., 1999b], on shortterm and ultrashort-term oscillations over the historic period [Broecker and Denton, 1989; Solomina, 1999] and in the Holocene and Pleistocene [Broecker and Denton, 1989; Thompson et al., 1997; etc.], and using examples of longterm oscillations and of the general climatic trend in the Cenozoic [Dingle and Lavelle, 1998; Fot'janova and Serova, 1994], Cretaceous [Frakes, 1999; German, 1993; Krasheninnikov et al., 1990], and Permian [Chumakov, 1995a]. It is very important that the in-phase character of these oscillations is traceable across various latitudes, including low, of both hemispheres. Thus, the Medieval Ice Age and its preceding Viking Age with a warm climate were established from and a cooling and a warming both at the Arctic Circle and in the Sargasso Sea, respectively [Keigwin, 1996]. Holocene ultrashort-term climate oscillations are recorded in 


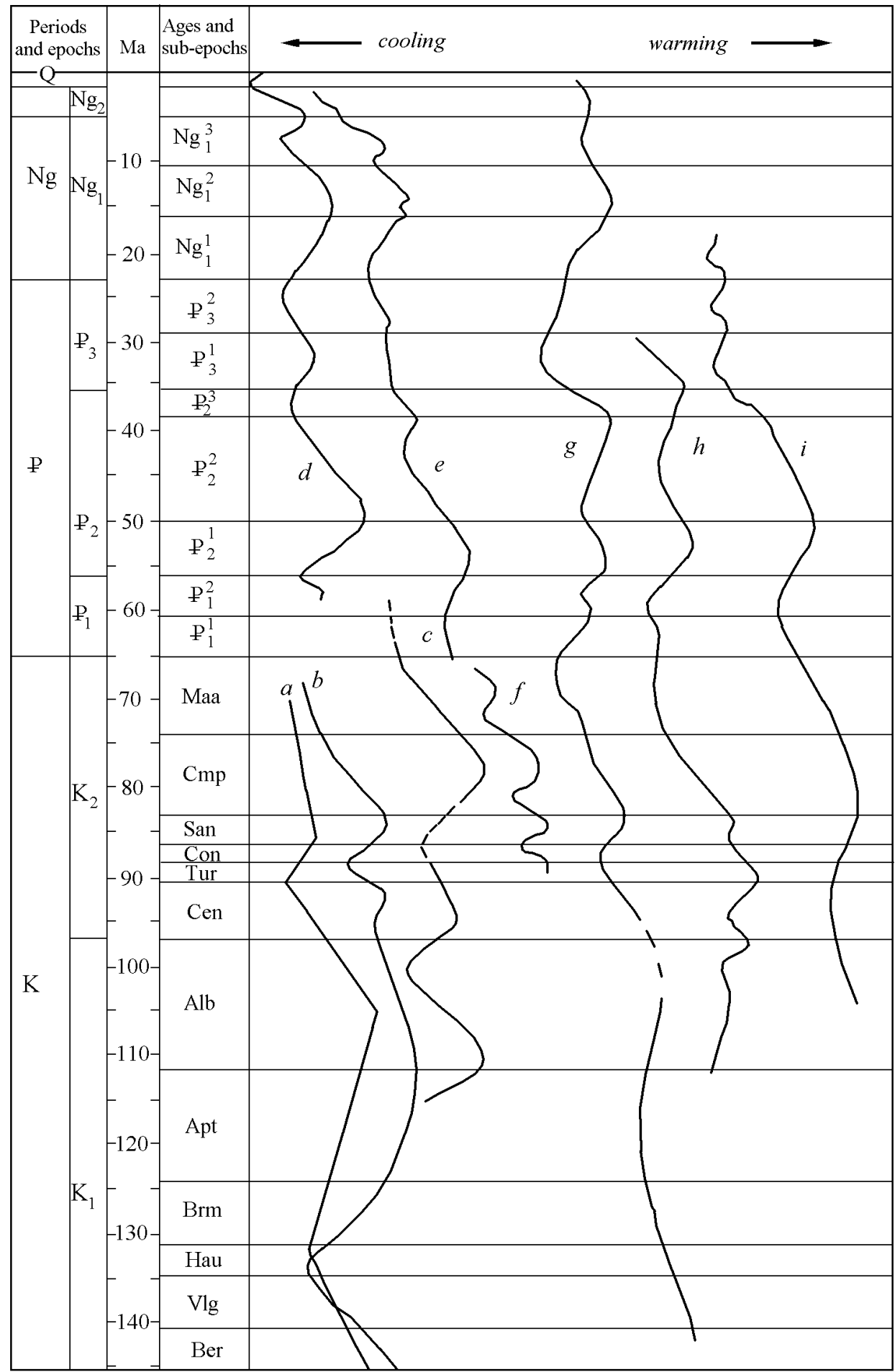

Figure 7. Correlation of Cretaceous and Cenozoic climate oscillations at various latitudes in the Northern and Southern Hemispheres: a - conventional average annual temperatures in Siberia from oxygen isotope and Ca/Mg data [Gol'bert, 1987]; b - relative temperature changes in northern Siberia based on sedimentologic and paleontologic data [Velichko et al., 1994]; c - relative temperature changes in mountain regions of NE Asia based on paleobotanical data [Krasheninnikov et al., 1990]; d - relative changes of January temperature in Northeast Siberia [Velichko et al., 1994]; e - relative temperature changes in the Koryak Highland and Kamchatka based on paleobotanical and foraminifer data [Fot'janova and Serova, 1994]; f - temperatures in the Northwest Pacific based on oxygen isotope and paleobotanical data [Zakharov et al., 1999a]; $\mathrm{g}$ - surface water temperatures at low latitudes based on oxygen isotope data [Douglas and Woodruff, 1981]; $\mathrm{h}$ - surface water temperatures at middle latitudes in the Indian Ocean based on oxygen isotope data [Clarke and Jenkyns, 1999]; $\mathrm{i}$ - relative temperature changes in Antarctic Peninsula based on geochemical and other data [Dingle and Lavelle, 1998]. 
polar regions and in Equatorial Africa [Stager and Mayewski, 1997]. The last glacial maximum in the Pleistocene, marked by glaciation at high and middle latitudes, was expressed by cooling at low latitudes. It is fixed in equatorial South America by a $700-1200 \mathrm{~m}$ depression of the snow line and of the accumulation areas of mountain glaciers [Broecker and Denton, 1989] and by the oxygen isotope signature of their ice. In Equatorial Brazil, cooling is recorded geochemically, by noble gases in underground waters, and in Equatorial Africa, Sumatra, and New Guinea, by the lowering of the snow line and vegetation belts [Ninglian et al., 1999]. The last Glacial and its preceding Interglacial were expressed in the classical form in high and middle latitudes of the Earth, whereas near the equator they were reflected by perceptible oscillations of the temperature of surface waters [Lea et al., 2000]. The respective climate oscillations were manifested on lowlatitude land areas, in particular in Java, as well [van der Kaars and Dam, 1995]. In the Late Cretaceous and Cenozoic, the general cooling trend, as well as long-term climatic oscillations superimposed on it, although differing in amplitudes, were expressed in similar ways at high and middle latitudes in northeastern Asia [Fot'janova and Serova, 1994; German, 1993; Krasheninnikov et al., 1990; Velichko et al., 1994; Zakharov et al., 1999a], in surface and deep waters of the ocean at low latitudes [Douglas and Woodruff, 1981], at middle southern latitudes in the Indian Ocean [Clarke and Jenkyns, 1999], and in Antarctica [Dingle and Lavelle, 1998]. With rare exceptions, all these regions display warming in the Cenomanian, Santonian, Campanian, Early and Late Eocene, and Middle Miocene, and cooling in the Maastrichtian, terminal Eocene to Oligocene, and the second half of the Miocene to Pliocene (Figure 7).

The above data suggest that the broad spectrum of climate oscillations (ultrashort-term, short-term, long-term, and ultralong-term) were global, synchronous, and in-phase. This leads to the important conclusion that global climatic oscillations resulted from changes in the Earth's heat balance [Chumakov, 1995a], rather than from redistribution of heat in the biosphere only, as has been occasionally proposed [CLIMAP..., 1976; Nikolaev, 2000; etc.]. It should be stressed that comprehensive study of global oscillations is of a great interest paleoclimatically. Identifying these oscillations restricts essentially the number of likely candidates for the causes of global climatic changes.

3.5. Regional climatic oscillations. Regional climatic oscillations are and, undoubtedly, must have been sufficiently common in the past. Meteorological, geographic, and historical geology data demonstrate that these oscillations are driven by mega- and macrogeographic factors, such as changes in the position, size, and configuration of continents, seas, and oceans and in their orography, as well as by landscape changes. An example of regional climatic oscillations in the past is furnished by the Turonian-Coniacian warming in Alaska, induced by the opening and widening of the pre-cordilleran passage ("Western Seaway") and the relative cooling in Northeast Asia due to the closure of the seaway between Asia and Alaska [Spicer and German, 1998]. Further examples of regional climatic oscillations related to the opening and closure of seaways are provided by climatic oscillations in the Paleogene and Neogene of Western Siberia and the Arctic region [Akhmetiev, 1996].

\section{Conclusions}

In light of the above, the Earth's climate history does not appear to be a mere succession of random events. It seems to be rather coherent, the slow irreversible cooling of the Earth's surface during the past 3 b.y. having been superimposed by a rather regular system of periodic oscillations.

For a highly complex open system such as the Earth's climate system, the conclusion that climate has been evolving in a coherent manner appears surprising. The inference suggests itself that the Earth's climate system has been nearly stationary-state, and that among the multitude of processes bearing on the Earth's climate there were a small number of those most influential, "governing" processes with periodic attractors. At the present, the following "governing" processes can be suggested:

(1) Variations in the intensity of tectonic, magmatic, and metamorphic processes, responsible for ultralong-term (150 m.y.) and long-term (a few tens of m.y.) climatic oscillations. The periods of ultralong-term oscillations, contrary to the widely accepted notion, differ essentially from the duration of the galactic year. They might be linked to geodynamic processes in the Earth [Dobretsov, 1999], albeit other, astronomical causes cannot be ruled out either.

(2) Variations in the orbital parameters and the tilt of the Earth's axis of rotation, inducing short-term, Milankovitch climate oscillations. The nature of these variations is validated by numerous studies and further confirmed by the fact that they manifested themselves throughout the Phanerozoic, irrespective of the multiple changes in the geologic, geographic, climatic, and biotic situations on Earth.

(3) Fluctuations in the solar activity, driving ultrashortterm climatic oscillations. Evidently, there also existed some other "governing" climatic processes, in particular those responsible for medium-term climatic oscillations.

The concomitant factors discussed above (the arrangement of continents, oceanic circulation, greenhouse gases, orography, impact events) and many others, apparently, merely modified, to some extent or another, the conditions created by the "governing" factors, reinforcing or weakening the influence of the latter and expanding or shortening the timespan of climatic events. However, even combinations of several "non-governing" factors were not sufficient to trigger glaciation (see Table 1). In this context, evidently, some analogy can be drawn to weather oscillations. Seasonality is caused by the Earth's rotation around the Sun at a highly constant period, but winters may be cooler or warmer and longer or shorter depending on the characteristics of circulations in the atmosphere and hydrosphere.

The above data and conclusions require further refinement, but they show clearly that the study of past and the most ancient climates is indispensable for a correct understanding of how the climate system of our planet functions, because this study provides climatologists with the results of numerous large-scale and unique experiments set up by $\mathrm{Na}$ - 
ture itself. This offers an opportunity for testing empirically our theoretical concepts.

Acknowledgments. This work was supported by the Russian Foundation for Basic Research (Project No. 02-05-64335).

\section{References}

Akhmedov, A. M., Glacial-volcanoclastic basinal facies of the Kalevian on the Baltic shield (in Russian), Proc. I All-Russian Paleovolcanol. Symp., August 20-25, 2001, Petrozavodsk, pp. 69-70, Petrozavodsk, 2001.

Akhmetiev, A. M., Ecological crises of the Paleogene and Neogene in extratropical Eurasia and their putative causes, Paleont. J., 30, (6), 738-748, 1996.

Anderson, R. Y., and W. E. Dean, Filling the Delaware Basin: hydrologic and climatic controls on the Upper Permian Castile Formation Varved evaporite, in The Permian of Northern Pangea, Vol. 2: Sedimentary Basins and Economic Resources, edited by P. A. Scholle, T. M. Peryt, and D. S. Ulmer-Scholle, pp. 61-78, Springer-Verlag, Berlin, Heidelberg, 1995.

Avdeev, A., On the issue of galactic geochronology (in Russian), Izv. Akad. Nauk Kazakh. SSR, Ser. Geol., 2, pp. 1-8, Nauka, Alma-Ata, 1973.

Barash, M. S., N. S. Blyum, I. I. Burmistrov, et al., NeogeneQuaternary Paleoceanology: Microfossil Evidence, 285 pp., Nauka, Moscow, 1989.

Beaufort, L., Y. Lancelot, P. Camberlin, O. Cayre, E. Vincent, F. Bassinot, and L. Labeyrie, Insolation cycles as a major control of equatorial Indean Ocean primary production, Science, 278, (5342), 1451-1454, 1997.

Bekker, A., A. J. Kaufman, J. A. Karhu, N. J. Beukes, Q. D. Swart, L. L. Coetzee, and K. A. Eriksson, Chemostratigraphy of the Paleoproterozoic Duitshland Formation, South Africa: implications for coupled climate changes and carbon cycling, Amer. J. Sci., 301, (3), 261-286, 2001.

Berner, R. A., and Z. Kothavala, GEOCARB III: a revised model of atmospheric $\mathrm{CO}_{2}$ over Phanerozoic time, Amer. J. Sci., 301, Febr., 182-204, 2001.

Bianchi, G. G., and I. N. McCave, Holocene periodicity in North Atlantic climate and deep-ocean flow south of Iceland, Nature, 397, 515-517, 1999.

Bozhko, N. A., Supercontinent cycles, crustal growth episodes, and global geodynamic inversions in the bipolar Earth evolution, in Supercontinents in the Geologic Evolution of the Precambrian, pp. 33-35, Institute of the Earth's Crust, Irkutsk, 2001.

Broecker, W. S., and G. H. Denton, The role of ocean atmosphere organisations in glacial cycles, Geochim Cosmochim. Acta, 5, (10), 2465-2501, 1989.

Brown, D. A., K. S. W. Campbell, and K. A. W. Crook, The geological evolution of Australia and New Zeeland, 335 pp., Pergamon Press, Oxford, 1968.

Budyko, M. I., A. B. Ronov, and A. L. Yashin, History of the Atmosphere, 208 pp., Gidrometeoizdat, Leningrad, 1985.

Caputo, M. V., and J. C. Crowell, Migration of glacial centers across Gondwana during Paleozoic Era, Geol. Soc. Amer. Bull., 96, 1020-1036, 1985.

Chambers, M. H., D. S. L. Lawrence, B. W. Sellwood, and A. Parker, Annual layering in the Upper Jurassic Kimmeridge clay formation, UK, quantified using an ultra- high resolution SEM-EDX investigation, Sedimentary Geology, 137, 9-23, 2000.

Chapman, M. R., and N. J. Shackleton, Global ice-volume fluctuations, North Atlantic ice-rafting events, and deep-ocean circulation changes between 130 and $70 \mathrm{ka}$, Geology, 27, (9), 795-798, 1999.
Chumakov, N. M., Precambrian Tillites and Tilloids, 202 pp., Nauka, Moscow, 1978.

Chumakov, N. M., Glacial events of the past and their geological significance, Palaeogeogr., Palaeoclim., Palaeoecol., 51, (1/4), 319-346, 1985.

Chumakov, N. M., The problems of old glaciations (PrePleistocene glaciogeology in the USSR), Sov. Sci. Rev. G. Geology, (1), 1-208, 1992.

Chumakov, N. M., The Middle Siberian glacial horizon of the Riphean (in Russian), Stratigr. Geol. Korrelyatsiya, 1, (1), 21-34, 1993a.

Chumakov, N. M., Paleoclimatic Issues in the Studies of PreQuaternary Biospheric Evolution, pp. 106-122, Nauka, Moscow, 1993b.

Chumakov, N. M., Climatic oscillations and biotic events (in Russian), Geol. Geofiz., 36, (8), 30-39, 1995a.

Chumakov, N. M., The issue of a warm biosphere (in Russian), Stratigr. Geol. Korrelyatsiya, 3, (3), 3-14, 1995b.

Chumakov, N. M., The key section of Vendian glacial deposits in South Urals (Kurgashly Formation, Krivoluksky graben), in The Urals: Critical Issues of Geodynamics and Stratigraphy, edited by A. L. Knipper, S. A. Kurenkov, and M. A. Semikhatov, pp. 138-153, Nauka, Moscow, 1998.

Chumakov, N. M., Periodicity of principal glacial events and their correlation to the Earth's interior activity (in Russian), Dokl. Ross. Akd. Nauk, 378, (5), 656-659, 2001a.

Chumakov, N. M., The general trend of climate changes on Earth over the past 3 billion years (in Russian), Dokl. Ross. Akad. Nauk, 381, (5), 652-655, 2001b.

Chumakov, N. M., and O. V. Oleinik, Rhythmicity of climate changes in the Phanerozoic and Vendian, in Atlas of Temporal Variations of Natural, Human-induced, and Social Processes, Nauchyi Mir, Moscow, 2001.

Chumakov, N., and M. Zharkov, Climate during Permo-Triassic biospheric rearrangements, Papers 1 and 2 (in Russian), Stratigr. Geol. Korrelyatsiya, 2002.

Clarke, L. J., and H. C. Jenkyns, New oxygen isotope evidence for long-term Cretaceous climatic change in the Southern Hemisphere, Geology, 27, (8), 699-702, 1999.

CLIMAP, The surface of the ice-age Earth, Science, 191, 11311144, 1976.

Condon, M. A., The geology of the Carnarvon basin, W. Australia: Stratigraphy. Pt. 2. Permian, Bur. Miner. Resour. Geol. Austral. Bull., 77, 191 pp., 1967.

Crowell, J. C., Pre-Mesozoic ice ages: their bearing on understanding the climate system, Geol. Surv. Amer. Memoir 192, 106 pp., 1999.

D'Agrella-Filho, M. S., I. G. Pacca, W. Teixeira, et al., Paleomagnetic evidence for evolution of Mezo- to Neo-Proterozoic glacigenic rocks in central-eastern Brazil, Palaeogeogr., Palaeoclim.,

Palaeoecol., 80, 255-265, 1990.

Dergachev, V., The radiocarbon chronometer (in Russian), Priroda, 1, 3-15, 1994.

Dingle, R. V., and M. Lavelle, Late Cretaceous-Cenozoic climatic variations of the northern Antarctic Peninsula: new geochemical evidence and review, Palaeogeog., Palaeoclimatol., Palaeoecol., 141, 215-232, 1998.

Dobretsov, N., A regular periodicity of the glaucophane schist metamorphism: An illusion or a system? (in Russian), Petrologiya, 7, (4), 430-459, 1999.

Dobretsov, N., and A. Kirdyashkin, Estimating the global processes of matter exchange between the Earth's shells: Correlation of factual geological and theoretical data (in Russian), Dokl. Ross. Akad. Nauk, Geol. Geofiz., 39, (9), 1269-1280, 1998.

Dobretsov, N., and V. Kovalenko, Global changes of the natural environment (in Russian), Geol. Geofiz., 36, (8), 7-30, 1995.

Dodonov, A. E., The Quaternary Period of Middle Asia: Stratigraphy, correlation, and paleogeography, Doctoral Thesis, 44 pp., Geological Institute of the Russian Academy of Sciences, Moscow, 2001.

Douglas, J. G., and F. Woodruff, Deep sea bentic foraminifera, 
in The Sea, 7, edited by C. Emiliani, pp. 1233-1327, Wiley Interscience, N.Y., 1981.

Dupont, L. M., S. Jahns, F. Marret, et al., Vegetation change in equatorial West Africa: time-slices for the last $150 \mathrm{ka}$, Palaeoclim., Palaeogeog., Palaeoecol., 155, 95-122, 2000.

Ehrmann, W. U., M. J. Hambrey, J. G. Baldauf, J. Barron, B. Larsen, A. Mackensen, S. W. Wise, and J. C. Zachos, History of Antarctic glaciation: an Indian Ocean perspective, in Synthesis of Results from Scientific Drilling in the Indian Ocean, Geophysical Monograph, 70, 423-446, 1992.

Eriksson, P. G., R. Mazumder, S. Sarkar, P. K. Bose, W. Altermann, and $R$. van der Merwe, The 2.7-2.0 volcano-sedimentary record of Africa, India and Australia: evidence for global and local changes in sea level and continental freeboard, Precambr. Res., 97, 269-302, 1999.

Evans, D. A. D., Stratigraphic, geochronological, and paleomagnetic constraints upon the Neoproterozoic climatic paradox, Amer. J. Sci., 300, 347-433, 2000.

Fot'janova, L. I., and M. Ya. Serova, Comparison of palaeoclimatic data based on plant and foraminiferal evidence from the Cenozoic of Northeast Asia (Koryak hills, Kamchatka), in Cenozoic Plants and Climates of the Arctic, edited by M. C. Boulter and H. C. Fisher, NATO ASI Series, 127, 107113, Berlin, Heidelberg, Springer-Verlag, 1994

Frakes, L. A., Estimation of the global thermal state from Cretaceous sea surface and continental temperature data, Geol. Soc. Amer. Spec. Pap., 49-57, 1999.

Frakes, L. A., J. E. Francis, and J. I. Syrtus, Climate Modes of the Phanerozoic, 274 pp., Cambridge Univ. Press, 1992.

German, A., Phases and cyclicity of the development of Late Cretaceous floras in the Anadyr-Koryak sub-region (in Russian), Stratigr. Geol. Korrelyatsiya, 1, (1), 87-96, 1993.

Gevers, T. W., and W. Beets, Pre-Dwyka glacial periods in South Africa, Proc. 17th IGC, 6, 73-110, 1940.

Gol'bert, A. V., Fundamentals of Regional Paleoclimatology, Nedra, Moscow, 1987.

Golonka, J., and D. Ford, Pangean (Late Carboniferous-Middle Jurassic) paleoenvironment and lithofacies, Palaeogeogr., Palaeoclim., Palaeoecol., 161, (1-2), 1-34, 2000.

Golonka, J., M. I. Ross, and C. R. Scotese, Phanerozoic paleogeographic and paleoclimatic modeling maps, Canad. Soc. Petrol. Geologists, Memoir, 17, 1-47, 1994.

Hambrey, M. J., and A. M. Spencer, Late Precambrian glaciation of central East Greenland, Geoscience, 19, 53 pp., 1987.

Hambrey, M. J., W. B. Harland, N. M. Chumakov, et al. (Eds.), Earth's Pre-Pleistocene Glacial Record, 1004 pp., Cambr. Univ. Press., Cambridge, 1981.

Harland, W. B., Critical evidence for a great infra-Cambrian glaciation, Geol. Rundschau, 54, 45-91, 1964.

Harland.,W. B., Chronology of Earth's glacial and tectonic record, J. Geol. Soc. London, 138, 197-203, 1981.

Harland, W. B., R. L. Armstrong, A. V. Cox, L. E. Craig, A. G. Smith, and D. G. Smith, A geologic time scale 1989, 263 pp., Cambridge Univ. Press, Cambridge, 1990.

Herbert, T. D., J. Gee, and S. DiDonna, Precessional cycles in Upper Cretaceous pelagic sediments of the South Atlantic: Longterm patterns from high-frequency climate variations, Geol. Soc. Amer. Spec. Pap., 332, 105-118, 1999.

Hofmann, P. F., A. J. Kaufman, G. P. Halverson, and D. P. Schrag, A Neoproterozoic snowball Earth, Science, 281, 1342-1346, 1998.

Holmes, A., The Age of the Earth, Nelson, London, 1937.

House, M. R., Orbital forcing timescales: an introduction, in Orbital Forcing Timescales and Cyclostratigraphy, edited by M. R. House and A. S. Gale, Geol. Soc. Lond. Spec. Publ., $85,1-18,1995$.

Imbrie, J., J. D. Hays, D. G. Martinson, et al., The orbital theory of Pleistocene climate: support from a revised chronology of the marine ${ }^{18} \mathrm{O}$, in Milankovitch and Climate, pp. 269-305, Reidel, Dordrecht, 1984.

Karabanov, E., M. Kuz'min, D. F. Williams, et al., Global cooling events in Central Asia in the Late Cenozoic: Evidence from sedimentary record of Lake Baikal (in Russian), Dokl. Ross.
Akad. Nauk, 370, (1), 61-66, 2000.

Keigwin, L. D., Sedimentary record yields several centuries of data, Oceanus, 39, (2), 16-18, 1996.

Keller, B., The great glaciations in the Earth's history (in Russian), Sov. Geol., 9, 26-35, Nedra, Moscow, 1972.

Khain, V. E., Principal Issues of Modern Geoscience, 190 pp., Nauka, Moscow, 1995.

Khain, V. E., Tectonics of the Continents and Oceans: The Year 2000, 604 pp., Nauchnyi Mir, Moscow, 2001.

Khain, V., and K. Seslavinsky, Global rhythmicity in the Phanerozoic activity of the Earth's interior (in Russian), Stratigr. Geol. Korrelyatsiya, 2, (6), 40-63, 1994.

Khomentovsky, V., and A. Postnikov, Neo-Proterozoic history of the development of the Baikal-Vilyui branch of the Paleo-Asian Ocean (in Russian), Geotektonika, 3, 3-21, 2001.

Kotlyakov, V., and K. Lorius, The four climatic cycles: Evidence from glacial cores from the deep hole at Vostok Station, Antarctica (in Russian), Izv. Ross. Akad. Nauk, Ser. Geogr., 1, 7-19, 2000

Krasheninnikov, V., E. Lebedev, and I. Basov, On global climatic changes in Albian-Late Cretaceous time (in Russian), Izv. Akad. Nauk SSSR, Ser. Geol., 5, 3-13, 1990.

Krasilov, V. A., Environmental Protection: Fundamentals, Issues, Priorities, 174 pp., Institute of Environmental Protection, Moscow, 1992.

Larson, R. L., A. G. Fisher, E. Erba, and I. Premoli Silva (Eds.), Proc. Apricore-Albicore: A workshop Report on Global Events and Rhythms of the mid-Cretaceous, 4-9, October 1992, Perugia, Italy, 56 pp., 1993.

Lea, D. W., D. K. Pak, and H. J. Spero, Climate impact of Late Quaternary equatorial Pacific sea surface temperature variations, Science, 289, (5485), 1719-1724, 2000.

Lee, K. E., and N. C. Slowey, Cool surface waters of the subtropical North Pacific Ocean during the last glacial, Nature, 397, (11), 512-514, 1999.

Link, P. K., J. M. G. Miller, and N. Christie-Blick, Glacial-marine facies in a continental rift environment: Neoproterozoic rocks of the western United States Cordillera, pp. 29-46, Cambridge Iniv. Press., 1994.

Lisitsyn, A. P., Avalanche Sedimentation and Depositional Breaks in Seas and Oceans, 309 pp., Nauka, Moscow, 1988.

Lowenstein, T. K., J. Li, Ch. Brown, et al., 200 ky palaeoclimate record from Death Valley salt core, Geology, 27, (1), 3-6, 1999.

Lungersgauzen, G., Periodicity and climate changes of past geologic epochs and some issues of geochronology (in Russian), Dokl. Akad. Nauk SSSR, 108, (4), 707-710, 1956.

Marmo, J. S., and R. W. Ojakangas, Lower Proterozoic glaciogenic deposits, eastern Finland, Geol. Soc. Amer. Bull., 95, 1055-1062, 1984.

Martin, D. M., Depositional setting and implications of Paleoproterozoic glaciomarine sedimentation in the Hamersley Province, Western Australia, Geol. Soc. Amer. Bull., 2, 189-203, 1999.

Mason, R., Petrology of the Metamorphic Rocks, 263 pp., Allen and Unwin, London, 1978.

Mayr, F., Untersuchungen uber Ausmass und Folgen der Klima und Gletschershwankungen seit dem Beginn der Postglazialen Warmezeit: Ausgewahlte Beispiele aus den Stubaier Alpen in Tirol, Ztschr. Geomorphol., 8, 257-285, 1964.

Meert, J. C., and R. van der Voo, The Neoproterozoic (1000$540 \mathrm{Ma})$ glacial intervals: No more snowball earth? Reply, Earth Planet. Sci. Lett., 131, 123-125, 1995.

Miller, D. J., and K. A. Eriksson, Linked sequence development and global climate change: the Upper Mississippian record in the Appalachian basin, Geology, 27, (1), 35-38, 1999.

Mitchell, J. M., A prelimenary evaluation of atmospheric pollution as a cause of global temperature fluctuations of the past century, in Global Effect of Environmental Pollution, pp. 235250, Springer-Verlag, N.Y., 1970.

Mutterlose, J., and A. Ruffell, Milankovitch-scale palaeoclimate changes in pale- dark bedding rhythms from the Early Cretaceous (Hauterivian and Barremian) of eastern England and northern Germany, Palaeogeog., Palaeoclimatol., Palaeoecol., 154, 133-160, 1999. 
Nelson, D. R., A. F. Trendall, and W. Altermann, Chronological correlations between the Pilbara and Kaapvaal cratons, Precambr. Res., 97, 165-189, 1999.

Nikolaev, S. D., The evolution of oceanic climates in the Cenozoic, in The Issues of Pleistocene Paleogeography and Stratigraphy, pp. 179-201, Moscow State University, Moscow, 2000.

Ninglian, W., Y. Tandong, S. Yafeng, L. G. Tompson, et al., On the magnitude of temperature decrease in the equatorial regions during the Last Glacial Maximum, Sci. China, 42, 80-90, 1999.

Phillips World Atlas, 300 pp., Phillips, N.Y., 1986.

Poulsen, Ch. J., R. T. Pierrehumbert, and R. L. Jacob, Impact of oceanic dynamics on the simulation of the Neoproterozoic "snowball Earth," Geophys. Res. Lett., 28, (8), 1575-1578, 2001.

Preiss, W. V., (Compiler), The Adelaide Geosyncline-late Proterozoic stratigraphy, sedimentation, palaeontology and tectonics, Bull. Geol. Surv. S. Aust., 53, 438 pp., 1987.

Prueher, L. M., and D. K. Rea, Volcanic triggering of late Pliocene glaciation: evidence from the flux of volcanic glass and icerafted debris to the North Pacific, Palaeogeog., Palaeoclim., Palaeoecol., 173, 215-230, 2001.

Rampino, M. R., and S. Self, Volcanic winter and accelerated glaciation following the Toba supereruption, Nature, 359, (6390), 50-53, 1992.

Raymo, M. E., Global climate change: a three million year perspective, in Start of a Glacial, edited by G. J. Kukla and E. Went, NATO ASI Ser., Ser. I, Global Environmental Change, 3, 207-223, 1992.

Resolution of the III All-Russian Conference on the General Issues of the Subdivision of the Precambrian (in Russian), Stratigr. Geol. Korrelyatsiya, 9, (3), 101-106, 2001.

Ruddiman, W. F. (Ed.), Tectonic Uplift and Climate Change, 535 pp., Plenum Press, N.Y., 1997.

Salop, L., Precambrian tillites and the great glaciations (in Russian), Byull. Mosk. O-va Ispyt. Prirody, Otd. Geol., 48, (8), 74-80, 1973.

Schwarzbach, M., Das Klima der Vorzeit, 380 pp., F. Enke, Stuttgart, 1974.

Semikhatov, M. A., Refining radiometric ages for the lower boundaries of the Upper Riphean, Vendian, Upper Vendian, and Cambrian, Supplement 4, in Supplements to the Stratigraphic Code of Russia, pp. 95-107, All-Russian Geological Institute, St. Petersburg, 2000.

Semikhatov, M. A., K. A. Shurkin, E. M. Aksenov, et al., A new stratigraphic scale for the Precambrian in the USSR (in Russian), Izv. Akad. Nauk SSSR, Ser. Geol., 4, 3-16, 1991.

Semikhatov, M., M. Raaben, V. Sergeev, A. Veis, and O. Artemova, Biotic events and the positive isotope anomaly (in Russian), Stratigr. Geol. Korrelyatsiya, 7, (5), 3-27, 1999.

Smith, A. G., Paleomagnetically and tectonically based global maps for Vendian to Mid-Ordovician time, in The Ecology of the Cambrian Radiation, pp. 11-46, Columbia Univ. Press, N.Y., 2001.

Shnitnikov, A., The modern phase of decadal-scale variations of the mountain glaciation of the Northern Hemisphere (in Russian), Izv. Vsesoyuzn. Geogr. O-va, 93, (1), 3-35, 1961.

Solomina, O. N., Mountain Glaciation of Northern Eurasia in the Holocene, 263 pp., Nauchnyi Mir, Moscow, 1999.

Spicer, R. E., and A. B. German, Cretaceous climate of Asia and Alaska: Comparing paleobotanical evidence with a computer model (in Russian), Paleontol. Zhurn., 2, 3-18, 1998.

Stager, J. C., and P. A. Mayewski, Abrupt Early to Mid Holocene climate transition registered at the equator and the poles, $S c i$ ence, 276, (5320), 1834-1836, 1997.

Steiner, J., Lead isotope events of the Canadian Shield, ad hoc solar galactic orbits and glaciations, Precambr. Res., 6, 269274, 1978.

Stratigraphy of the USSR, Quaternary System, (1), 443 pp., Nedra, Moscow, 1982.

Sutcliffe, O. E., J. A. Dowdeswell, R. J. Whittington, J. N. Theron, and J. Craig, Calibrating the Late Ordovician glaciation and mass extinction by the eccentricity cycles of Earth's orbit, $\mathrm{Ge}$ ology, 28, (11), 967-970, 2000.
Thompson, L. G., T. Yaj, M. E. Davis, et al., Tropical Climate instability: the last glacial cycle from Qinghai-Tibetan ice core, Science, 276, (5320), 1821-1825, 1997.

Umbgrove, J. H., The Pulse of the Earth (2nd ed.), 358 pp., Martin Nijholf, Hague, 1947.

Vakhrameev, V. A., Jurassic and Cretaceous Floras and Earth Climates, 214 pp., Moscow, 1988.

Valdes, P. J., R. A. Spicer, B. W. Sellwood, and D. C. Palmer, Understanding past climates, CD-ROM, Gordon and Breach Sci. Publ., Reading, 1999.

van der Kaars, W. A., and M. A. C. Dam, A 135,000-year record of vegetational and climatic change from the Bandung area, WestJava, Indonesia, Palaeogeog., Palaeoclimatol., Palaeoecol., 117, 55-72, 1995.

Veevers, J. J., Tectonic-climatic supercycle in the billion-year plate-tectonic eon: Permian Pangean icehouse alternates with Cretaceous dispersed-continents greenhouse, Sedimentary Geology, 68, 1-16, 1990.

Velichko, A. A., The structure of thermal changes of MesoCenozoic paleoclimates: Evidence from the studies of Eastern Europe, in Earth Climates of Geologic Past, pp. 5-43, Nauka, Moscow, 1987.

Velichko, A. A., and V. P. Nechaev (Eds.), Changes in Climate and Landscapes over the Past 65 Million Years, pp. 43-83, GEOS, Moscow, 1999.

Velichko, A. A., V. A. Zakharov, S. A. Laukhin, and N. M. Chumakov, On the periodicity of climate oscillations in the Phanerozoic, in Ecosystem Rearrangements and Evolution of the Biosphere, (1), 109-113, Nedra, Moscow, 1994.

Visser, J. N. J., The Mid-Precambrian tillite in the Griqualand West and Transvaal Basins, South Africa, in Earth's Pre-Pleistocene Glacial Record, edited by M. J. Hambrey and W. B. Harland, pp. 180-184, Cambridge Univ. Press, 1981.

Visser, J. N. J., Episodic Palaeozoic glaciation in the Cape Karoo basin, South Africa, in Glacier Fluctuations and Climatic Change, edited by Oerlemans, pp. 1-12, Kluwer Acad. Publ., Boston, Dordrecht, 1989.

Visser, J. N. J., A review of the Permo-Carboniferous glaciation in Africa, in Late Glacial and Postglacial Environmental Changes, edited by I. P. Martini, pp. 169-191, Oxford Univ. Press, New York, Oxford, 1997.

Waterhouse, H. K., Orbital forcing of palynofacies in the Jurassic of France and the United Kingdom, Geology, 27, (6), 511-514, 1999.

Weedon, G. P., and W. A. Read, Orbital-climatic forcing of Namurian cyclic sedimentation from spectral analysis of the Limestone Coal Formation, Central Scotland, Geol. Soc. Spec. Pub., 85, 231-245, 1995.

Williams, G. E., Possible relation between periodic glaciation and the flexure of the Galaxy, Earth Planet. Sci. Lett., 26, 361369,1975 .

Williams, G. E., Milankovitch-band cyclicity in bedded halite deposits contemporaneous with Late Ordovician-Early Silurian glaciation, Canning Basin, Western Australia, Earth Planet. Sci. Lett., 103, 143-155, 1991.

Winkler, H. G. F., Petrogenesis of Metamorphic Rocks, 327 pp., Springer-Verlag, N.Y., 1976.

Wise, S. W., Jr., J. R. Breza, D. M. Harwood, and W. Wei, Paleogene glacial history of Antarctica, in Controversies in Modern Geology, pp. 133-171, Cambridge Univ. Press, Cambridge, 1991.

Woldstedt, P., Das Eiszeitalter, I, Enke, Stuttgart, 1954.

Wu, Y., Y.-M. Gong, C.-Y. Wang, and B.-H. Li, Orbital cyclostratigraphy of the Devonian Frasnian-Famennian transition in South China, Palaeogeog., Palaeoclimatol., Palaeoecol., 168, (3-4), 237-248, 2001.

Yasmanov, N., The galactic year and periodicity of geologic events (in Russian), Dokl. Ross. Akad. Nauk., 328, (3), 373-375, 1993.

Young, G. V., An extensive early Proterozoic glaciation in Norht America?, Palaeogeog., Palaeoclimatol., Palaeoecol., 7, 85-101, 1970.

Young, G. V., V. von Brunn, J. C. Gold, and W. E. L. Minter, 
Earth's oldest reported glaciation: Physical and chemical evidence from the Archean Mozaan Group ( 2.9 Ga) of South Africa, J. Geol, 106, 523-538, 1998.

Zachos, J., M. Pagani, L. Sloan, E. Thomas, and K. Billups, Trends, rhythms, and aberrations in global climate 65 Ma to present, Science, 292, 686-693, 2001.

Zakharov, V. A., Climatic fluctiations and other events in Mesozoic time of Siberian Arctic, Proc. Intern. Conf. Arctic Margins, Anchorage, MMS, 23-28, 1992.

Zakharov, Y. D., N. G. Boriskina, A. V. Ignatyev, K. Tanabe, Y. Shigeta, A. M. Popov, T. B. Afanasyeva, and H. Maeda, Palaeotemperature curve for the Late Cretaceous of the northwestern circum-Pacific, Cretaceous Res., 20, 685-697, 1999a.

Zakharov, V. G., L. P. Chernova, and T. E. Khromova, A link between oscillations of glaciers in Antarctica and mountain glaciers in Europe from the 1960s to 1990s, Materialy Glatsiogeologich. Issledovan., IGAN, 86, 123-127, 1999b.
Zakoldaev, Yu. A., Geochronometric scale of the Phanerozoic as a reflection of galactic orbital motion of the Solar System, in Stratigraphy and Paleontology of the Paleozoic of Arctica, pp. 157-166, Sevmorgeologiya, Leningrad, 1991.

Zarrina, E. P., I. I. Krasnov, D. B. Malakhovsky, and E. A. Spiridonova, Climatic rhythmicity of the late Pleistocene (northwestern and central European part of the USSR), in Paleoclimates and Glaciation Events in the Pleistocene, pp. 47-58, Nauka, Moscow, 1989.

Zubakov, V. A., Global climatic events of the Pleistocene, 288 pp., Gidrometeoizdat, Leningrad, 1986.

Zubakov, V. A., and I. I. Borzenkova, Paleoclimates of the Late Cenozoic, 214 pp., Gidrometeoizdat, Leningrad, 1983.

(Received 5 July 2002) 